\title{
INFLUÊNCIA DOS CORTICOSTERÓIDES NAS PROPRIEDADES BIOMECÂNICAS DA TRAQUÉIA DE COELHAS ALBINAS
}

\author{
Irene Raimundo dos Santos Silva
}

Dissertação apresentada ao Programa de PósGraduação Interunidades em Bioengenharia / Escola de Engenharia de São Carlos / Faculdade de Medicina de Ribeirão Preto / Instituto de Química de São Carlos, da Universidade de São Paulo para obtenção do título de Mestre em Bioengenharia.

Orientador: Prof. Dr. José Antônio Baddini Martinez.

\section{Ribeirão Preto}


A Deus,

Ser Supremo, que direciona os meus passos desde o dia em que entreguei a minha vida em suas mãos. Obrigada por tudo o que tem feito comigo. 


\section{AGRADECIMENTOS}

Aos meus pais, Severino e Iracema, que me ensinaram que o conhecimento, sabedoria e dignidade humana é tudo o que um homem pode deixar de herança para os seus filhos.

Ao Celinho, esposo, companheiro, amigo e confidente, obrigada por ter compreendido meus momentos de nervosismo, ausência e angústia. Casar com você foi a melhor decisão da minha vida. Te amo muito.

Aos meus filhos Leopoldo e Thales, gostaria de mostrar-lhes que vocês são os presentes mais preciosos que Deus me deu. Espero conseguir recompensá-los pela felicidade que me dão, tornando-os homens dignos e felizes.

Ao grande amigo Prof. Dr. Antônio Carlos Shimano. Quando o conheci sabia que aprenderia muito, porém não sabia que você e a sua família (Lúcia, Vítor e Vinicius), fossem ter um papel tão importante na minha vida. Deus há de recompensá-los por tudo o que fizeram por mim, pelo meu marido e pelos meus filhos. Ser mestre não é apenas transmitir conhecimentos, é ensinar a sabedoria da vida. Obrigada hoje e sempre.

Ao Prof. Dr. José Antonio Baddini, você foi muito mais do que um simples orientador, com sua incansável dedicação e capacidade de compreensão, transmitiu-me mais conhecimentos do que pensei que adquiriria com a realização deste trabalho.

Aos bibliotecários da UNESP de Ilha Solteira, Célia e João. Obrigada pela grande ajuda e pela verdadeira e inestimável amizade. 
Ao Marcos Shimano, obrigada pela ajuda de informática oferecida sempre tão pacientemente.

Aos técnicos do Laboratório de Bioengenharia, Chico e Henrique e as secretárias Terezinha e Janete, pelo carinho e disponibilidade.

A todos que direta ou indiretamente contribuíram para a realização deste trabalho. 


\section{SUMÁRIO}

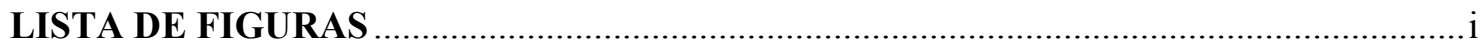

LISTA DE ABREVIATURAS, SIGLAS E SÍMBOLOS ....................................................iii

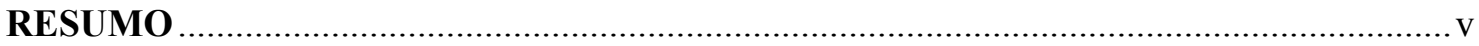

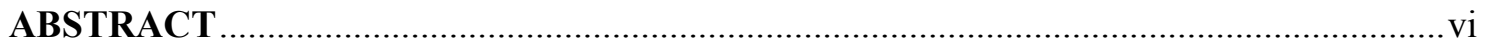

1 INTRODUÇÃO

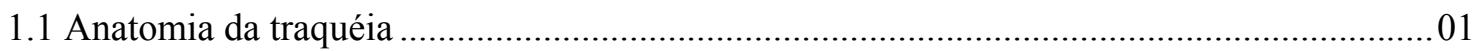

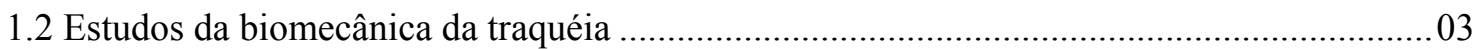

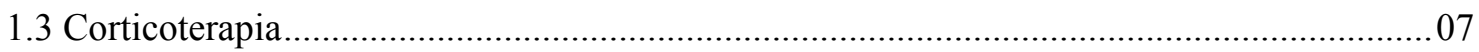

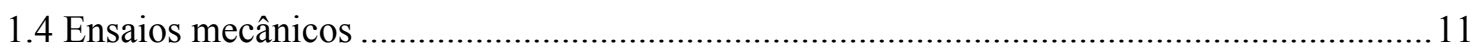

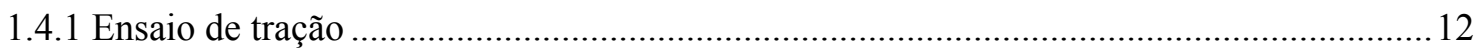

14.1.1 Módulo de Young e Curva de Esforço e Deformação ........................................................13

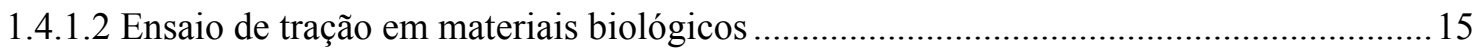

2 OBJETIVO

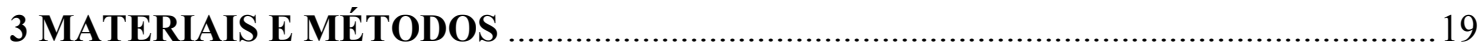




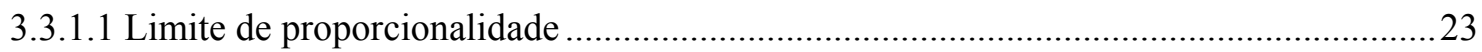

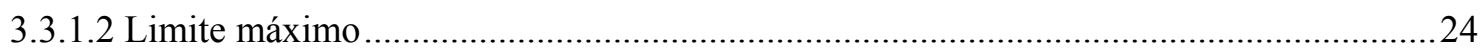

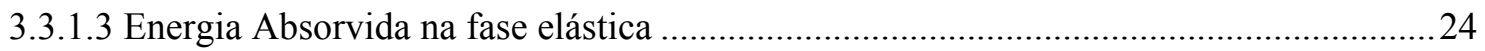

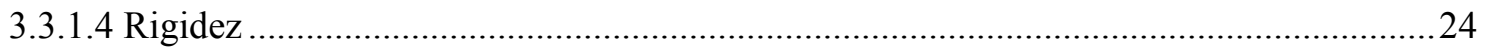

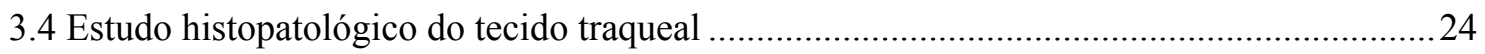

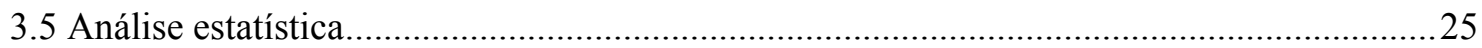

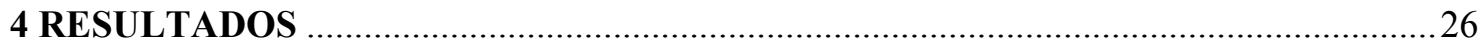

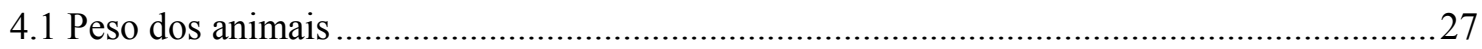

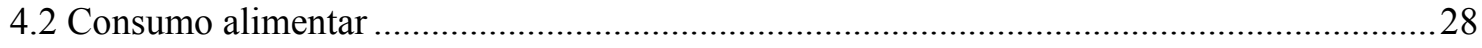

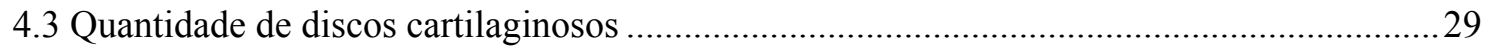

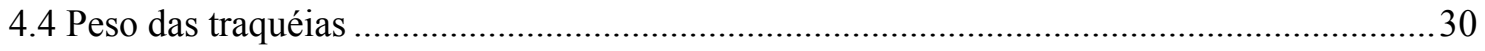

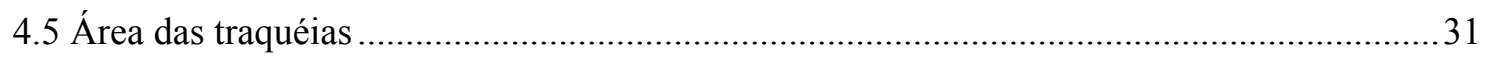

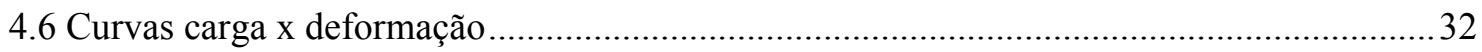

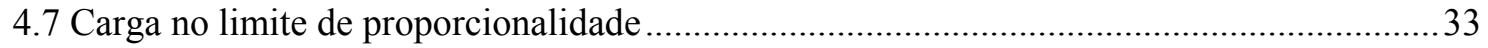

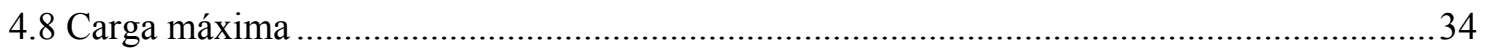


4.9 Alongamento no limite de proporcionalidade.

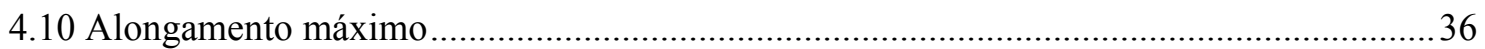

4.11 Energia absorvida na fase elástica (resiliência) .................................................................. 37

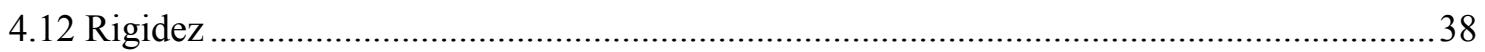

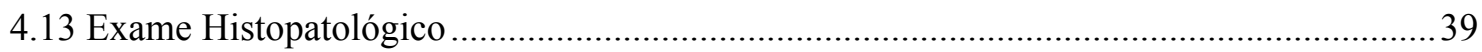

5 DISCUSSÃO

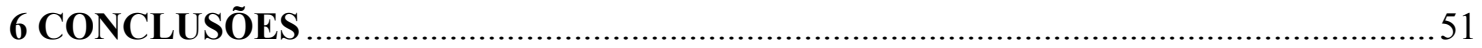

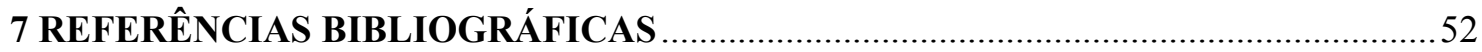




\section{LISTA DE FIGURAS}

FIGURA 01 - Corte transversal da traquéia .02

FIGURA 02 - Efeito de tensão simples do aço doce 14

FIGURA 03 - Retirada da traquéia proximalmente em sua junção com a cartilagem

cricóidea .20

FIGURA 04 - Cilindros de cobre sendo conectado a luz da traquéia.

FIGURA 05 - Ensaio de tração da traquéia sendo realizado na Máquina Universal de

Ensaio .22

FIGURA 06 - Gráfico carga x alongamento, ilustrando o limite de proporcionalidade ( LP ), a reta que representa a inclinação da curva $(\theta)$, e otriângulo formado pela união dos pontos de inicio do ensaio e LP. A letra $\underline{h}$ representa a altura, $\underline{b}$ a base e a a área do referido triângulo.

FIGURA 07 - Discos cartilaginosos sendo imerso em em formol tamponado para posterior estudo histopatológico

FIGURA 08 - Valores médios do peso inicial e final dos animais de ambos os grupos.......

FIGURA 09 - Valores médios de consumo alimentar. .28

FIGURA 10 - Quantidade de discos cartilaginosos 
FIGURA 11 - Valores médios do peso da traquéia

FIGURA 12 - Valores médios da área das traquéias

FIGURA 13 - Gráfico Carga X Alongamento das 10 traquéias das coelhas as quais foram administrados corticóide 32

FIGURA 14 - Gráfico Carga X Alongamento das 10 traquéias das coelhas as quais foram administrados solução salina 32

FIGURA 15 - Valores médios da carga aplicada no limite de proporcionalidade .33

FIGURA 16 - Valores médios da carga máxima aplicada .34

FIGURA 17 - Valores médios do alongamento no limite de proporcionalidade .35

FIGURA 18 - Valores médios do alongamento máximo .36

FIGURA 19 - Valores médios da energia absorvida na fase elástica. 37

FIGURA 20 - Valores médios da rigidez .38

FIGURA 21 - Aspecto microscópico do tecido traquial estudado corado por tricrômio de Masson (aumento de 200 vezes). A esquerda foto do grupo controle e a direita foto do grupo experimental 


\section{LISTA DE ABREVIATURAS, SIGLAS E SÍMBOLOS}

ACTH Hormônio adreno-corticotrópico

\begin{tabular}{ll} 
At & Área de secção transversal da traquéia \\
C & Grupo Controle \\
cm & centímetros \\
CRF & Fator liberador de corticotropina \\
D & Diâmetro externo da luz traqueal \\
d & Diâmetro interno da luz traqueal \\
E & Grupo Experimental \\
g & gramas \\
GC & Glicocorticóides \\
HC & Hidrocortisona \\
J & Joule \\
mg & Miligramas \\
Kg & Kilogramas \\
Kgf & Kilograma Força \\
\hline LP & Limite de proporcionalidade \\
\hline
\end{tabular}


MHz Mega hertz

ml Mililitros

mm milímetros

N Newton

SA Sociedade Anônima

W Watts 


\section{RESUMO}

Foram estudados os efeitos da metilprednisolona na traquéia de coelhas albinas adultas da raça Nova Zelândia. O objetivo deste estudo foi investigar os efeitos potenciais desta substância nas propriedades biomecânicas da traquéia de coelhas por meio de ensaio de tração axial. Os animais foram divididos em dois grupos. Dez coelhas do grupo controle receberam por via subcutânea $2 \mathrm{mg} / \mathrm{Kg} /$ dia de metilprednisolona diluída em solução salina. As dez coelhas do grupo controle receberam também de modo subcutâneo volumes proporcionais de solução salina. Após 21 dias, os animais foram sacrificados e suas traquéias submetidas a ensaio de tração e estudo histopatológico. Os animais do grupo experimental apresentaram peso significantemente inferior ao do grupo controle no final do tratamento $(\mathrm{C}$ $=3996 \pm 314 \mathrm{~g} \mathrm{x} \mathrm{E}=3555 \pm 373 \mathrm{~g}$ ). Os grupos não diferiram do ponto de vista estatístico quanto as seguintes variáveis: carga no limite de proporcionalidade $(\mathrm{C}=8,94 \pm 1,68 \mathrm{~N} \mathrm{x} \mathrm{E}=$ $8,93 \pm 1,52 \mathrm{~N})$; carga máxima $(\mathrm{C}=9,12 \pm 2,2 \mathrm{~N} \times \mathrm{E}=9,57 \pm 1,90 \mathrm{~N})$; alongamento no limite de proporcionalidade $\left(\mathrm{C}=(683 \pm 2,08) \times 10^{-3} \mathrm{~m} \times \mathrm{E}=(6,05 \pm 1,50) \times 10^{-3} \mathrm{~m}\right)$; alongamento máximo $\left(\mathrm{C}=(7,44 \pm 2,60) \times 10^{-3} \mathrm{~m} \mathrm{x} \mathrm{E}=(6,85 \pm 1,55) \times 10^{-3} \mathrm{~m}\right)$; energia absorvida na fase elástica $\left(\mathrm{C}=(28,70 \pm 14,43) \times 10^{-3} \mathrm{~J} \times \mathrm{E}=(27,75 \pm 11,06) \times 10^{-3} \mathrm{~J}\right)$; rigidez $\left(\mathrm{C}=(1,08 \pm 0,41) \times 10^{3} \mathrm{~N} / \mathrm{m} \times \mathrm{E}=(1,2 \pm 0,37) \times 10^{3} \mathrm{~N} / \mathrm{m}\right)$. Concluiu-se ao término deste estudo que não houve alterações morfológicas e biomecânicas das traquéias estudadas, no entanto, os animais do grupo experimental sofreram significante emagrecimento ao final do tratamento, quando comparado ao grupo experimental. 


\begin{abstract}
The effects of methilprednisolona in the adult's trachea albinos female rabbits were studied. The goal of this study was examine the potential effects of this armorial traction. The animals were divided in two groups. Ten female rabbits of control group received by way of subcutaneous $2 \mathrm{mg} / \mathrm{kg} /$ day of salt bed diluted solution. These ten female rabbits of the control group also received by way of subcutaneous proportional volumes of salt bed solution. After 21 days, the animals were sacrificed and their trachea were subjected to traction tests and anatomical pathological studies. Animals of the experimental group presented inferior weight significant from the control group in the end of the treatment $(\mathrm{C}=$ $8,94 \pm 314 \mathrm{~g} \mathrm{X} \mathrm{E}=3555 \pm 373 \mathrm{~g}$ ). The groups didn't differ from the statistic point of view as regards of the following variables: limit load of proportionality $(\mathrm{C}=8,94 \pm 1,68 \mathrm{~N} \mathrm{X} \mathrm{E}=$ $8,93 \pm 1,52 \mathrm{~N})$; maxim load $(\mathrm{C}=9,12 \pm 2,2 \mathrm{~N} \mathrm{X} \mathrm{E}=9,57 \pm 1,90 \mathrm{~N})$; stretch out on the limit of proportionality $\left(\mathrm{C}=(683 \pm 2,08) \times 10^{-3} \mathrm{~m} \mathrm{X} \mathrm{E}=(6,05 \pm 1,50) \times 10^{-3} \mathrm{~m}\right)$; maxim stretch out $\left(\mathrm{C}=(7,44 \pm 2,60) \times 10^{-3} \mathrm{~J} \mathrm{X} \mathrm{E}=(6,85 \pm 1,55) \times 10^{-3} \mathrm{~J}\right)$; absorbed energy in the elastic phase $\left.(\mathrm{C}=28,70 \pm 14,43) \times 10^{-3} \mathrm{~m} \mathrm{~J} \mathrm{X} \mathrm{E}=(27,75 \pm 11,06) \times 10^{-3} \mathrm{~J}\right)$; rigidity $(\mathrm{C}=1,08 \pm$ $\left.0,41) \times 10^{-3} \mathrm{~N} / \mathrm{mXE}=(1,2+0,37) \times 10^{-3} \mathrm{~N} / \mathrm{m}\right)$. It was concluded in the end of the treatment that there weren't any morphological and biomechanical alterations of the trachea studied, although, the animals of the experimental group suffered a significant slimming in the end of the treatment when compared with the experimental group.
\end{abstract}




\section{INTRODUÇÃO}

O sistema respiratório compõe-se de pulmões e vias aéreas. No interior dos pulmões, as vias aéreas se ramificam até atingirem pequenos sacos aéreos que contêm múltiplas dilatações denominadas alvéolos, locais onde ocorrem trocas gasosas entre o sangue e o ar (BETHLEM, 1996).

Para que o oxigênio alcance os alvéolos é indispensável, em primeiro lugar, que o ar atmosférico seja levado até a superfície respiratória, através de um sistema de estruturas aéreas condutoras (TARANTINO, 1997). Além da função de condução essas estruturas também são responsáveis pelo aquecimento, umidificação e filtragem do ar que será conduzido até os alvéolos. De um modo abrangente, podem ser considerados elementos desse sistema aéreo condutor o nariz, as fossas nasais, a naso-faringe, a laringe, traquéia, brônquios e bronquíolos.

\subsection{Anatomia da Traquéia}

De um ponto de vista restrito, a traquéia marca o inicio do sistema condutor, freqüentemente denominado de árvore traqueobrônquica, e é denominada via respiratória de primeira geração. É uma estrutura tubular que começa na cartilagem cricóide e prossegue através do pescoço até o mediastino. A traquéia se estende até a articulação entre o manúbrio e o corpo do esterno (Ângulo de Louis). Neste ponto, ela se divide nos dois brônquios principais (RUPPEL, 2000; GUYTON, 1997). 
A traquéia está situada quase na linha média do pescoço. No mediastino superior ela desvia discretamente para a direita, deixando espaço para que a aorta passe no seu lado esquerdo. Existe uma cartilagem pontiaguda na ponta da bifurcação traqueal. Essa cartilagem, denominada carina, divide o fluxo de ar para o lado direito ou esquerdo, onde se origina o brônquio direito e esquerdo respectivamente (RUPPEL, 2000).

A traquéia do humano adulto possui um diâmetro médio de 2,0 a $2,5 \mathrm{~cm}$ e tem um comprimento que varia de 10 a $12 \mathrm{~cm}$. O suporte da traquéia vem dos 16 a 20 anéis cartilaginosos em forma de "C". Cada anel traqueal possui uma altura de 4 a $5 \mathrm{~mm}$. As cartilagens estão envolvidas por uma membrana fibroelástica, e as fibras elásticas formam uma camada importante nas paredes de todas as partes subseqüentes da árvore respiratória. No dorso da traquéia um músculo fino liso e densas fibras de tecido conjuntivo se estendem entre as extremidades das cartilagens mantendo os anéis unidos e fechando as aberturas dos anéis em "C". Essa estrutura fornece suporte e permite a variação no diâmetro da traquéia (RUPPEL, 2000; SPENCE, 1991).

A porção da traquéia intratorácica é particularmente afetada pelas diferenças de pressão através de suas paredes. Uma intensa compressão ocorre durante a tosse. Pressões intratorácicas elevadas fazem com que a parede posterior colapse parcialmente para o interior. Isso estreita a luz traqueal e gera altos fluxos de ar (RUPPEL, 2000).

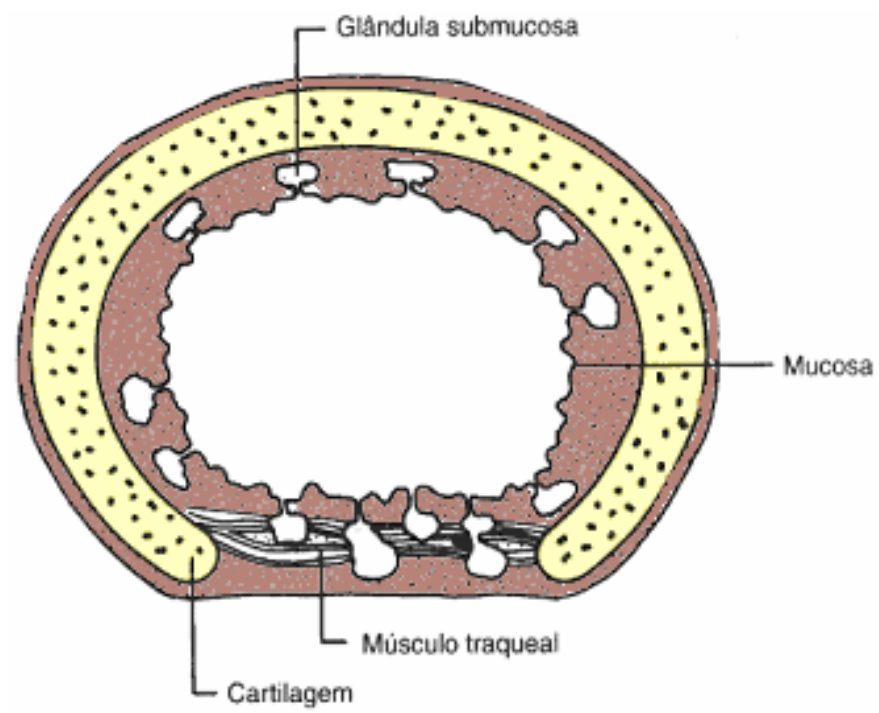

FIGURA 1 - Corte transversal da traquéia. 
A traquéia é revestida por uma membrana mucosa de epitélio pseudoestratificado colunar ciliado que contém numerosas glândulas mucosas. Como os cílios se movem para cima, eles tendem a carregar partículas estranhas e excessiva secreção mucosa para fora, desde os pulmões até a faringe, onde elas são deglutidas (SPENCE, 1991).

\subsection{Estudos da biomecânica da traquéia}

Atualmente a Engenharia colabora com um vasto campo que beneficia a Medicina e Reabilitação. O objetivo desta união é oferecer ao homem melhores condições de vida, saúde, recuperação anátomo-funcional e sobrevivência equilibrada (RAMOS, 1979). Um dos importantes benefícios da bioengenharia é a avaliação das propriedades mecânicas de materiais ou tecidos que compõem o corpo humano ou que são utilizados para substituir ou reparar alguma parte dele. Para a determinação destas propriedades de materiais ou tecidos são realizados, ensaios mecânicos.

A traquéia é um elemento fundamental das vias respiratórias. Devido a sua estrutura tubular e composição predominantemente fibro-cartilaginosa, apresenta características fisiológicas e de mobilidade ímpares. Ela não se comporta apenas como um tubo estático meramente conectando a laringe com os brônquios. Ao invés disso, é uma estrutura dinâmica que deve responder ao estresse da respiração, proteção das vias aéreas e deglutição (MEYERS \& BISHOP, 1978). Apesar disso, são escassos os estudos da literatura voltados a investigação de aspectos relacionados às suas propriedades biomecânicas.

STEPHENS \& KROMER (1971) estudaram uma série de componentes elásticos no músculo liso da traquéia de cães e observaram que quando uma tensão máxima foi aplicada ao músculo esquelético a série de componentes elásticos distendeu-se em 1,5 a $3 \%$, o músculo cardíaco em 8 a $10 \%$ e o músculo liso traqueal distendeu-se 7,5\%. Estes 
autores concluíram, então, que existem diferenças quantitativas na aquiescência de valores da série de componentes elásticos do músculo esquelético, cardíaco e músculo liso traqueal, porém qualitativamente todos demonstram curvas exponenciais de comprimento/tração similares. Concluíram, também, que a aquiescência da série de componentes elásticos do músculo liso traqueal é menor do que em qualquer músculo liso nos mamíferos. Isto sugere que o músculo traqueal desperdiça menos energia da série de componentes elásticos durante uma contração isométrica.

COBURN \& PALOMBINI (1972) estudaram os efeitos das mudanças na tensão intraluminar ativa de músculos traqueais de cães in situ, sobre as relações pressãovolume tempo dependente. Segmentos de 8 a $14 \mathrm{~cm}$ da traquéia intratorácica foram isolados e adaptados a uma câmara fechada, sendo sua luz preenchida com solução salina. Os animais foram ventilados através de uma cânula conectada à traquéia, acima da carina e distalmente ao segmento estudado. As relações de pressão-volume do segmento puderam ser estudadas, mudando-se o volume do lúmen e registrando-se as alterações da pressão intraluminal. Foram registradas a tensão de relaxamento ao longo de um período de tempo de quatro segundos, começando no pico de pressão e, logo em seguida, a tensão de relaxamento foi registrada por mais de 11 segundos.

Pequena ou nenhuma mudança foi observada por esses autores, com o aumento da tensão ativa traqueal em segmentos parcialmente colapsados, sugerindo que as propriedades viscosas do músculo liso traqueal têm pouca influência na pressão volumetempo dependente. Estes dados apóiam o conceito de que as propriedades de tensão-tempo dependente das vias aéreas são principalmente um resultado das propriedades viscoelásticas ou viscoplásticas do músculo liso das vias aéreas, e são muito influenciadas pela mudança do tônus ativo da musculatura lisa.

POWELL (1975) avaliou as propriedades mecânicas estáticas da traquéia e da árvore brônquica de cães. Os cães foram anestesiados e imobilizados com a traquéia 
paralela a ação da gravidade e seu diafragma também paralisado. Foram realizadas broncografias lateral direita afim de identificar a posição do brônquio e da carina. Dois pontos foram marcados nestas estruturas para que se pudesse medir seu deslocamento.

A primeira broncografia foi realizada com os pulmões a nível de Capacidade Residual Funcional. A segunda broncografia foi realizada após a provocação de pneumotórax bilateral, perfurando-se o quarto espaço intercostal direito e esquerdo. $\mathrm{Na}$ segunda etapa deste estudo pesos foram implantados nas regiões hilares direita e esquerda e novas broncografias foram feitas para verificar o deslocamento $(\mathrm{mm})$ em função do peso (gr), antes e depois do pneumotórax. Neste estudo foi observado que antes da realização do pneumotórax, os hilos suportaram cerca de $23 \%$ do peso pulmonar, porém, após o pneumotórax os hilos suportaram $93 \%$ do peso pulmonar. Estes resultados apóiam a hipótese de que o peso dos pulmões é suportado em grande parte pelas variações regionais da pressão pleural.

MEYERS \& BISHOP (1978) investigaram as relações força-deslocamento em diferentes níveis das membranas intercartilaginosas de traquéias de cães. Para tanto utilizaram sistemas receptores de mercúrio firmemente atados a parede externa da traquéia ao nível da membrana cricotraqueal e nos espaços localizados entre o primeiro e segundo, segundo e terceiro, e terceiro e quarto arcos cartilaginosos. Os autores evidenciaram que os segmentos da traquéia eram mais móveis e sofriam maior distensão do que os segmentos inferiores em resposta a extensão da cabeça e deglutição. A ressecção do terceiro, quarto, quinto e sexto anéis cartilaginosos, seguida de anastomose término-terminal, levou a redução da mobilidade da membrana cricotraqueal, bem como a um aumento do stress desenvolvido pela estrutura para um mesmo deslocamento.

Posteriormente esse mesmo grupo investigou as propriedades elásticas de uma traquéia humana isolada utilizando um dispositivo que promovia tração longitudinal da estrutura por meio de uma bomba hidráulica (MEYERS, BISHOP \& PETERS, 1980). Os 
autores observaram que o comportamento da traquéia humana foi muito semelhante ao das traquéias caninas. Sua mobilidade é maior nos segmentos mais altos, e menor nos segmentos terminais. Além disso, a elasticidade da traquéia humana mostrou ser muito maior do que a elasticidade das traquéias caninas. Esse último fenômeno foi justificado pelo fato da traquéia humana ter uma parede membranosa posterior maior do que a dos cães.

HAMAIDE et al. (1998) avaliaram a biomecânica e as propriedades bioquímicas da traquéia de cães, estudando o efeito da idade e das características locais dos anéis cartilaginosos. Eles avaliaram 8 cães imaturos (6 meses de idade) e 8 cães adultos (de 2 a 3 anos de idade) realizando cortes histológicos do anel cartilaginoso proximal e outro do anel cartilaginoso distal. Nos anéis cartilaginosos foi avaliada a quantidade de água e proteoglicans e as características biomecânicas quanto a tensão e relaxamento. Embora anteriormente os estudos da literatura indicassem que com o aumento da idade, o conteúdo de água e proteoglicans da cartilagem hialina diminuía e a quantidade de colágeno permanecia constante, os resultados dos estudos de HAMAIDE et al. (1998) contraria tais achados. Neste estudo, foi encontrado que a cartilagem dos cães adultos têm significante aumento no conteúdo de proteoglicans e uma significante baixa do conteúdo de água em comparação a cães jovens. Tal estudo mostrou também que as propriedades biomecânicas dos anéis cartilaginosos da traquéia de cães são alterados com a idade, ou seja, ocorre aumento da tensão com o desenrolar da maturidade.

As modificações das propriedades biomecânicas dos anéis cartilaginosos da traquéia dos cães adultos observadas no estudo de HAMAIDE et al (1998) apresentaram correlação significante com a diminuição do conteúdo de água, mas pequena correlação com o aumento do conteúdo de proteoglicans.

Estes autores concluíram ainda que independente do local da traquéia, as propriedades biomecânicas e bioquímicas são as mesmas em cães da mesma idade.

WANG et al. (2000) estudaram a influência da idade sobre as propriedades mecânicas da membrana da mucosa traqueal em coelhos e constataram que as propriedades 
mecânicas da mucosa não mudam com o amadurecimento das espécimes. No entanto, ao retirarem uma amostra retangular de tecido longitudinalmente ao comprimento da traquéia e compararem as propriedades mecânicas de um tecido retangular do mesmo tamanho, cortado no sentido circunferencial, puderam concluir que a membrana apresenta maior tensão quando tracionada no sentido longitudinal do que quando tracionada no sentido circunferencial.

\subsection{Corticoterapia}

Glicocorticóides (GC) são hormônios de natureza esteroídica que atuam em uma variedade de sistemas e tecidos. O produto natural, cortisol ou hidrocortisona (HC) é considerado o principal hormônio do córtex adrenal e a partir de modificações introduzidas em moléculas foram sintetizados inúmeros derivados com atividade GC maior e mais prolongada, cujas indicações terapêuticas são amplas e variadas.

Os glicocorticóides são essenciais para muitas funções orgânicas, agindo em todos os tecidos e desencadeando inúmeras respostas. Entre estas ações inclui-se o catabolismo protéico, a lipólise e a glicogênese hepática. A ação mais característica dos glicocorticóides está relacionada com o metabolismo intermediário dos carboidratos .

Quando produzido em excesso, ou administrado em altas doses por via sistêmica, os glicocorticóides interferem também em outras funções. Algumas delas são benéficas, tais como a supressão da resposta alérgica, inflamatória e imunológica, porém, outras trazem efeitos indesejáveis, como a retenção hidrosalina, a espoliação de cálcio, potássio e hidrogênio e o antagonismo ao hormônio do crescimento.

Atualmente a corticoterapia prolongada é indicada em inúmeras condições, tais como no tratamento de câncer, doenças auto-imunes, moléstias inflamatórias crônicas 
como, por exemplo, artropatias, e na manutenção de imunossupressão em pacientes transplantados de órgãos. Uma outra condição em que a corticoterapia pode vir a ser usada em altas doses ou por tempo prolongado é na presença de patologias pulmonares agudas e crônicas tais como doença pulmonar obstrutiva crônica, doenças intersticiais pulmonares e asma grave.

A manutenção da corticoterapia em altas doses ou por longos períodos pode associar-se a uma série de efeitos colaterais, tais como: diabetes mellitus, edema e ganho de peso, fragilidade capilar, perda de massa muscular, hipertensão arterial, catarata, osteoporose, etc.

As alterações provocadas pelos glicocorticóides no metabolismo ósseo em particular são bastante conhecidas. Concentrações excessivas de glicocorticóides in vivo diminuem a formação óssea e podem causar necrose óssea. A redução da formação óssea está associada com redução da densidade óssea e ao decréscimo dos níveis séricos de osteocalcina, um marcador da função osteoblástica (HUANG \& ZENG, 1999). Ossos acometidos por osteoporose também mostram uma redução no número de osteoblastos (CANALIS \& DELANY, 2002). Como os osteoblastos exibem receptores para glicocorticóides é possível que tais hormônios desempenhem efeitos diretos sobre as células da linhagem osteoblástica. Por outro lado, admite-se atualmente que os esteróides também possam interferir na função osteoclástica indiretamente, por meio da indução da produção de fatores solúveis e de membrana por osteoblastos e outras células estromais (HUANG \& ZENG, 1999; ANGELI et al, 2002).

Os efeitos dos glicocorticóides sobre os tecidos conectivos são igualmente bem reconhecidos. Tais drogas demonstram ações adversas sobre processos pré-fibróticos e de cicatrização de incisões cirúrgicas e feridas. Esses efeitos decorrem de ações inibidoras em diversos níveis tais como nos processos inflamatórios, proliferação fibroblástica, síntese e degradação do colágeno, deposição de glicosaminoglicans, angiogênese, etc (RANG, 
DALE, RITTER, 1996). Nesse complexo mecanismo está envolvido o antagonismo a diversos fatores de crescimento e citoquinas (BEER, FASSLER, WERNER, 2000).

Acumulam-se ainda na literatura evidências de que os glicocorticóides apresentem efeitos deletérios igualmente sobre estruturas compostas por tecido cartilaginoso.

CHANDLER \& WRIGHT (1958) e CHANDLER, WRIGHT, HARTFALL (1958) mostraram pela primeira vez que, em um número significante de indivíduos com artrite reumatóide, a melhora funcional secundária a injeção intraarticular de hidrocortisona era seguida por evidências radiológicas de destruição excessiva e acelerada da articulação.

CARAZZATO et al. (1980) estudaram os efeitos da infiltração local de metilprednisolona, xilocaina, água destilada e perfuração com agulha na transição músculo tendinea do tríceps sural em 30 ratos de linhagem Wistar. Os animais foram divididos em dois grupos de 15 . Um grupo recebeu $0,2 \mathrm{ml}$ de corticóide a direita e $0,2 \mathrm{ml}$ de solução de xilocaína a $2 \%$ à esquerda, o outro grupo foi infiltrado a direita, com $0,2 \mathrm{ml}$ de água destilada, e a esquerda foi feita somente uma perfuração com agulha do mesmo calibre, não sendo injetada nenhuma substância. Os animais foram sacrificados em cinco intervalos de tempo diferentes (24 horas, 1, 2, 3, e 4 semanas). O tríceps sural destes animais foi submetido a análise histológica e teste de resistência. Estes autores observaram necrose músculo tendínea no grupo infiltrado com xilocaína e corticóide, sendo que neste último ocorreu significante diminuição da resistência tecidual.

BEHRENS, SHEPARD, MITCHELL (1975) administraram acetato de hidrocortisona semanalmente na cavidade articular de joelhos de coelhos por intervalos variando entre duas e 12 semanas. A medida que o número de injeções aumentavam os autores evidenciaram o surgimento de cistos e fissuras nas zonas médias das cartilagens articulares. Observaram ainda um decréscimo linear no conteúdo de proteoglicans, bem como evidências da redução da síntese de proteínas e colágeno. 
Mais recentemente PAPACRHISTOU, ANAGNOSTOU, KATSORHIS (1997), trabalhando com coelhos injetados na articulação do joelho com acetato de betametasona, observaram que o corticosteróide levou a alterações morfológicas dos condrócitos com aumento do seu tamanho e do número de vacúolos e lisossomos citoplasmáticos. Foram observadas ainda distorções da forma dos núcleos e redução do número total de organelas citoplasmáticas.

É importante ser enfatizado que os efeitos dos glicocorticóides sobre o tecido cartilaginoso pode se dar mesmo quando a droga é administrada por via sistêmica.

HINUCHI et al. (1980) investigaram os efeitos morfológicos da administração diária intramuscular de hidrocortisona, durante quatro a 12 semanas, sobre a morfologia da cartilagem acetabular de coelhos adultos. O uso de corticosteróides sistêmicos foi associado a redução do volume do retículo endoplasmático rugoso e do aparelho de Golgi dos condrócitos. Foi observado ainda redução dos microvilos celulares e da espessura da matrix cartilaginosa peri-celular. Para os autores tais resultados sugerem fortemente que a síntese de proteoglicans e proteínas pelos condrócitos seja afetada pelo uso de esteróides sistêmicos. Tais efeitos já se iniciariam com o uso de doses terapêuticas e se acentuariam com o uso de maiores concentrações das drogas ou pelo seu uso prolongado.

Posteriormente PODBIELSKI \& RAISS (1985), investigando os efeitos da administração de dexametasona sistêmica sobre a morfologia de cartilagens articulares de joelhos de ratos, chegaram a conclusões semelhantes. Nesse estudo a porcentagem de condrócitos mortos aumentou progressivamente com o uso de maiores doses do esteróide, sendo aproximadamente $21 \%$ superior a do grupo controle após a administração de um total de $5 \mathrm{mg}$ de dexametasona ao longo de 42 dias.

Muito embora a quase totalidade das investigações dos efeitos dos glucocorticóides sobre os tecidos cartilaginosos tenha sido feito em cartilagens articulares, há evidência de que tais efeitos seriam comuns ao tecido cartilaginoso de vários órgãos. 
ITANI et al. (1992) trataram coelhos com hidrocortisona intramuscular nas doses de 5 $\mathrm{mg} / \mathrm{kg} /$ dia durante 4 semanas . Após esse período fizeram estudos de microscopia eletrônica nas cartilagens dos joelhos e das traquéias. Os autores constataram reduções das áreas do retículo endoplasmático rugoso nos condrócitos localizados tanto nas cartilagens articulares, como também nas cartilagens traqueais. Tais resultados sugerem fortemente que o uso de glucocorticóides, em altas doses ou por longos períodos, leve a prejuízos da síntese protéica em células cartilaginosas localizadas em qualquer ponto do organismo animal.

Na hipótese dos efeitos deletérios da corticoterapia serem pronunciados nas cartilagens e demais tecidos conectivos traqueais, tornariam os seus usuários susceptíveis a complicações respiratórias potencialmente graves. A fraqueza da parede traqueal poderia levar a complicações particularmente sérias em indivíduos traqueostomizados ou submetidos a ventilação mecânica invasiva, sujeitos a compressão interna dos discos cartilaginosos pelo sistema de oclusão da luz traqueal por balão (cuff).

\subsection{Ensaios Mecânicos}

O comportamento mecânico dos materiais é dado pela análise das suas propriedades mecânicas inerentes. Fazem parte das propriedades mecânicas: a dureza, que é a resistência do material à penetração; a ductilidade que é a capacidade do material em se deformar; a fragilidade, capacidade do material se quebrar com o mínimo de deformação; o módulo de elasticidade, que é uma medida da rigidez do material determinada na fase elástica, e a resiliência que é a energia absorvida na fase elástica (ROCHA, 1989).

Estas propriedades podem ser determinadas por meio de dados colhidos da observação do comportamento de estruturas já existentes, mas a forma que apresenta maior confiabilidade é mediante testes padronizados que proporcionam resultados comparáveis e 
reprodutíveis. Estes testes denominados ensaios mecânicos, são divididos em destrutivos e não destrutivos. Os primeiros inutilizam o material testado e são denominados de acordo com a direção de aplicação da força em: ensaio de tração, de compressão, de cisalhamento, torção, etc. Os ensaios não destrutivos são realizados com o uso, por exemplo, de raios X, ultra-som, entre outros.

Nos ensaios pode-se usar o objeto em sua totalidade ou parte dele, em forma de corpo de prova, que por motivo de facilidade de padronização e comodidade técnica é mais utilizado.

Os ensaios podem ainda ser classificados, de acordo com a velocidade na qual a carga é aplicada, em estáticos (ou quase estáticos) e dinâmicos. No primeiro a carga é aplicada em baixa velocidade, o que permite a observação das reações do material. No ensaio dinâmico a velocidade de aplicação da carga é alta. Quanto mais rapidamente um corpo de prova for carregado, maior será a absorção de energia antes da falha (ROCKWOOD JÚNIOR et al., 1995).

\subsubsection{Ensaio de tração}

Dentre os ensaios, o de tração é considerado o mais importante, pela facilidade de execução e reprodutibilidade dos resultados. Consiste em submeter um material a um esforço que tende a esticá-lo ou alongá-lo promovendo deformação (SOUZA, 1977).

Durante o ensaio é aplicada uma força de tração na direção axial sobre determinado objeto (corpo de prova) de dimensões conhecidas e sob condições controladas. O objeto tende a alongar-se e as cargas e deformações são medidas por meio de um extensômetro e registradas, concomitantemente. 
Enquanto ocorrem as deformações, as forças exteriores que estão atuando no corpo produzem trabalho que é transformado em energia. Segundo ROOCKWOOD JÚNIOR et al (1995), energia é a capacidade de efetuar trabalho, e trabalho é o produto de uma força movendo-se através de um deslocamento. Sendo assim, energia de deformação é a capacidade que um corpo é capaz de absorver alterando sua forma sob a aplicação de uma carga externa.

Ao realizar o ensaio deve-se tomar o cuidado de alinhar bem o corpo de prova, com a finalidade de assegurar a aplicação do esforço na direção do seu eixo longitudinal.

\subsubsection{Módulo de Young e Curva de Esforço e Deformação}

Quando uma faixa elástica e complascente é esticada, se removermos a força deformadora, a faixa voltará ao seu comprimento de repouso; ou seja, houve uma deformação de estiramento que é recuperável e isto é reconhecido como deformação plástica. Eventualmente, se a deformação aumentar, chegará a um ponto em que o material falha. Isto é conhecido como o ponto de ruptura.

A dureza ou módulo de elasticidade de um material é determinada pelo declive da curva carga $\mathrm{X}$ deformação durante a amplitude da resposta elástica e é representativo da resistência do material à carga à medida que a estrutura deforma-se. Essa é uma resposta que ocorre em muitos materiais incluindo ossos, tendões e ligamentos (HAMILL \& KNUTZEN, 1999). Estes eventos podem ser visualizados, submetendo-se um corpo de prova a um esforço de tração onde a deformação resultante vai ser representada na 
plotagem de um gráfico. A seguir segue o exemplo de um aço doce sendo submetido a um efeito de tensão simples.

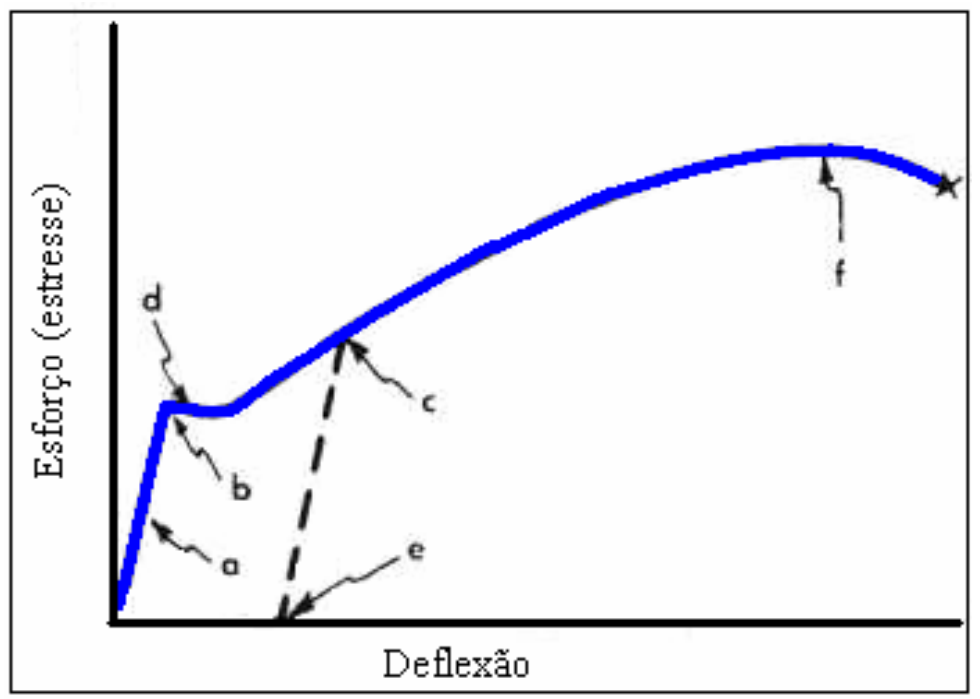

FIGURA 2 - Efeito de tensão simples do aço doce

Pode se ver que a primeira porção desta curva é linear; a deformação aumenta proporcionalmente ao esforço, até que o ponto $b$ seja atingido. $\mathrm{O}$ ponto $b$ conhecido como ponto de cessão ou limite de proporcionalidade, denota o término da região elástica da curva. Se em qualquer ponto ao longo deste gradiente até o ponto $b$ a carga for removida, o corpo de prova retomará a sua forma de repouso. A inclinação desta curva é uma medida da rigidez do material; o gradiente sendo conhecido como módulo de elasticidade ou módulo de Young.

A curva do ponto $b$ até $x$ que representa no gráfico o ponto onde ocorre a falha, mostra que a deformação aumenta muito mais rapidamente à medida em que é acrescentado mais esforço. Esta é a região plástica da curva, onde uma deformação permanente foi produzida no material. Se a carga for removida no ponto $c$, haverá alguma 
recuperação e a curva será paralela ao módulo de Young, mas haverá uma deformidade permanente que está representada no gráfico pelo ponto $e$.

Com a aplicação de uma carga, um esforço máximo será alcançado, representado no gráfico pelo ponto $f$, significando a resistência final à tração, ou seja, é o ponto de maior estresse e ou esforço que o material é capaz de suportar antes de fraturar. Além desse ponto, a deformação aumenta com o esforço diminuído; isto ocorre porque o material afina-se, fazendo um colo, ou seja, a secção transversal diminui, devido aos esforços de cisalhamento. Um material que sofre deformidade plástica é chamado dútil, e aqueles que falham logo após o ponto de cessão são quebradiços.

Observando a área do gráfico, embaixo da curva, podemos obter a quantidade de energia absorvida pelo material. Se for um material muito rígido, o ponto de cessão vai ser representado no gráfico em um ponto mais elevado, porém demonstrará ser um material muito mais quebradiço e com menor capacidade de absorver energia antes de falhar. Essa energia é medida em Joules $/ \mathrm{m}^{3}$.

\subsubsection{Ensaio de tração em materiais biológicos}

Apesar das diferenças entre os materiais biológicos e os materiais usados na engenharia, os equipamentos utilizados nestas áreas sugerem temas de estudos na sua interface. Algumas técnicas de análise estática e dinâmica de materiais utilizadas em engenharia podem ser adaptadas aos estudos de ossos e outros tecidos orgânicos (SHIMANO \& SHIMANO, 2000). Embora os primeiros ensaios destinados a tração de materiais biológicos tenha se iniciado com ossos, hoje existem inúmeros estudos que relatam estes mesmos ensaios em tecidos moles.

SANTOS (1996) realizou ensaios de tração em 26 espécimes constituídos de 52 ligamentos ( 26 coracoacromiais e 26 coraclaviculares); obtidos de 26 cadáveres humanos 
do sexo masculino do Serviço de Verificação de Óbtos da Faculdade de Medicina da Universidade Federal de Pernambuco. Este autor, concluiu que do ponto de vista do comportamento mecânico, os ligamentos coracoacromiais revelaram-se menos resistentes à carga máxima aplicada em relação aos coracoclaviculares. Porém, quando foram consideradas as energias absorvidas na fase elástica e os limites de proporcionalidade, os ligamentos coracoacromiais apresentaram valores médios superiores aos do coracoclaviculares. Em todos os ligamentos ensaiados os locais de ruptura foram nas origens ou nas inserções ósseas e não no corpo ligamentar. Tendo em vista as propriedades mecânicas analisadas nesta pesquisa este autor sugere que o ligamento coracoacromial é um bom substituto nos casos de ruptura dos ligamentos coracoclaviculares.

Posteriormente, MENEZES (1997) investigou no Laboratório de Bioengenharia da Faculdade de Medicina de Ribeirão Preto (USP) o efeito da aplicação do ultra-som terapêutico na reparação da lesão muscular experimental em coelhos, mediante a avaliação mecânica, utilizando ensaios de tração. Foi realizada uma lesão por esmagamento no músculo reto anterior do quadríceps direito e esquerdo em 26 coelhos da raça Nova Zelândia. Após três dias da lesão, os animais foram tratados em um lado com ultra-som terapêutico com tipo de onda pulsada, freqüência de $1 \mathrm{MHz}$ e intensidade de $0,5 \mathrm{~W} / \mathrm{cm}^{2}$ por 5 minutos, durante 10 dias consecutivos. O músculo contra lateral serviu como controle e sofreu apenas esmagamento. Após três dias do término da aplicação, os animais foram sacrificados e os músculos submetidos a ensaio de tração na Máquina Universal de Ensaio, com célula de carga de $200 \mathrm{Kgf}$ e velocidade de $4,5 \mathrm{~mm} /$ minuto. Foram analisados os resultados dos ensaios de 36 músculos, mostrando que os músculos tratados pelo ultra-som apresentaram diferença significativa na deformação máxima, carga e deformação no limite de proporcionalidade, e na energia na fase de deformação elástica. Estes resultados sugeriram que a aplicação do ultra-som terapêutico pode ser benéfica para melhorar a qualidade da reparação da lesão muscular aguda. 
Em função do exposto fica claro que os ensaios de tração são um método útil e adequado para a análise das propriedades mecânicas dos tecidos moles, capaz de detectar mudanças induzidas por intervenções terapêuticas. Além disso, os corticosteróides administrados em altas doses guardam o potencial, ainda não adequadamente investigado, de promover alterações deletérias ao nível traqueal. Dessa forma, torna-se importante a realização de estudo investigando os efeitos dos corticosteróides sobre as propriedades biomecânicas dos tecidos traqueais empregando-se ensaios de tração. 


\section{OBJETIVO}

O objetivo deste trabalho foi investigar os efeitos potenciais da corticoterapia nas propriedades biomecânicas da traquéia de coelhos, avaliadas por meio de ensaio de tração axial. 


\section{MATERIAIS E MÉTODOS}

Nesta pesquisa foram estudadas a influência da corticoterapia nas características patológicas e propriedades biomecânicas e geométricas da traquéia de 20 coelhos adultos fêmeas da raça Nova Zelândia e com peso médio de 3.856 g. Os coelhos foram fornecidos pelo Biotério Central do Campus da Universidade de São Paulo em Ribeirão Preto. Os animais foram preparados na sala de cirurgia do Laboratório de Bioengenharia da Faculdade de Medicina de Ribeirão Preto.

\subsection{Preparo dos animais}

Os animais foram divididos em dois grupos, um controle e outro experimental. O grupo experimental foi composto por dez coelhos nos quais foram administrados, durante 21 dias e no período da manhã, injeções subcutâneas de metilprednisolona (Solumedrol ${ }^{\circledR}$; Pharmacia-Up-John S.A. - Puurs - Bélgica), diluída em solução salina, nas doses de $2 \mathrm{mg} / \mathrm{kg} /$ dia. Foram realizadas correções dessas doses às segundas, quartas e sextas feiras, levando-se em conta alterações dos pesos dos animais. Os animais foram alimentados com ração padrão normal e água a vontade. A quantidade de alimento consumida foi medida a cada dois dias a fim de verificar se a introdução da medicação causava alterações do consumo alimentar. Tal medida foi realizada pesando-se a alimentação 
do comedouro quando mesmo era cheio e a cada 2 dias antes que o mesmo fosse novamente completada.

No grupo controle, também composto por dez animais, foi aplicada a mesma metodologia, no entanto, foram administrados diariamente por via subcutânea volumes proporcionais de solução salina apenas.

\subsection{Preparo da traquéia para o ensaio}

No $22^{\circ}$ dia após o inicio da administração do medicamento, os animais de ambos os grupos foram sacrificados, utilizando-se doses letais do anestésico Thiopental (1 grama diluída em $40 \mathrm{ml}$ de soro fisiológico), de modo intravenoso, até que se provocasse parada dos batimentos cardíacos. Em seguida procedeu-se a extração da traquéia, retirandose inicialmente a pele do animal e realizando-se uma incisão na caixa torácica de modo a retirar o esterno, facilitando assim a visualização da traquéia e permitindo uma análise macroscópica das vísceras do animal. A traquéia foi seccionada proximalmente em sua junção com a cartilagem cricóidea, através de incisão realizada no ligamento cricotraqueal, e distalmente, no último anel cartilaginoso que antecede a carina.

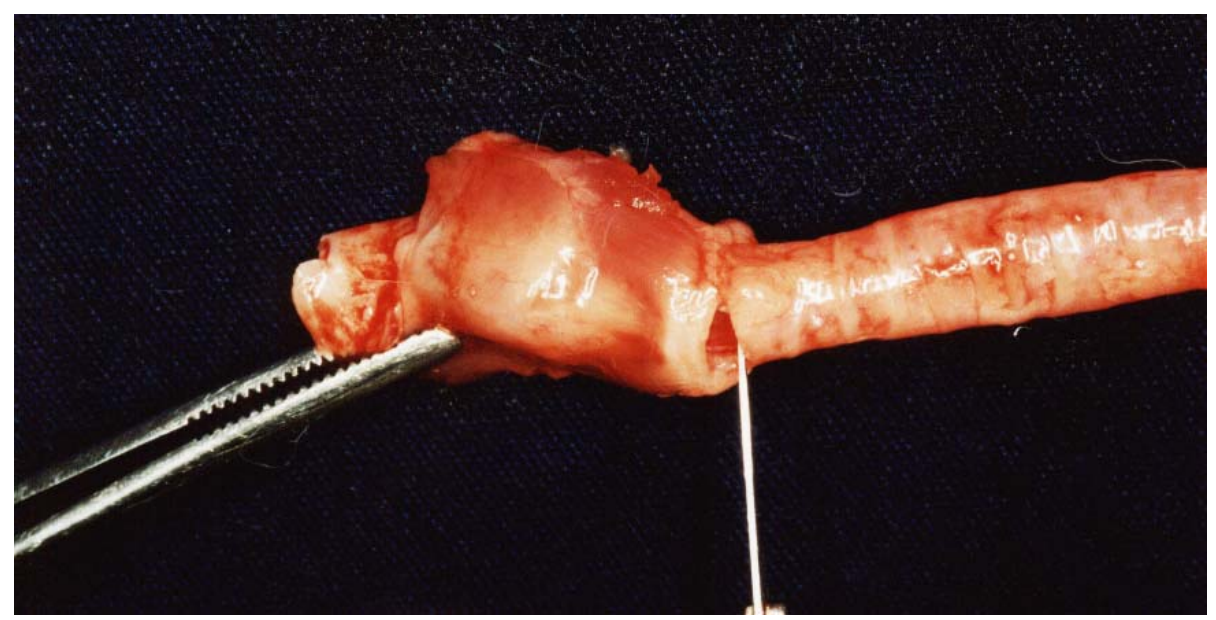

FIGURA 3 - Retirada da traquéia proximalmente em sua junção com a cartilagem cricóidea 
Durante todo o procedimento cirúrgico a traquéia foi irrigada com soro fisiológico. Após a sua retirada pesou-se a mesma e mediu-se o seu diâmetro interno (d) e externo (D) proximal e distal. Com os valores dos diâmetros de $\mathrm{D}$ foi calculado a área da secção transversal da traquéia $\left(A_{t}\right)$, utilizando a seguinte fórmula:

$A_{t=\pi / 4\left(D^{2}-d^{2}\right)}$

\subsection{Ensaio de tração}

Os ensaios de tração foram realizados na Máquina Universal de Ensaio do Laboratório de Bioengenharia da FMRP-USP. Para realizar os ensaios, cilindros especiais de cobre foram confeccionados, com diversos diâmetros e comprimento de $6 \mathrm{~mm}$. Os mesmos foram conectados na luz da traquéia em suas extremidades proximais e distais para realizar o apoio ao acessório externo da Máquina Universal de Ensaio que realiza a apreensão da traquéia.

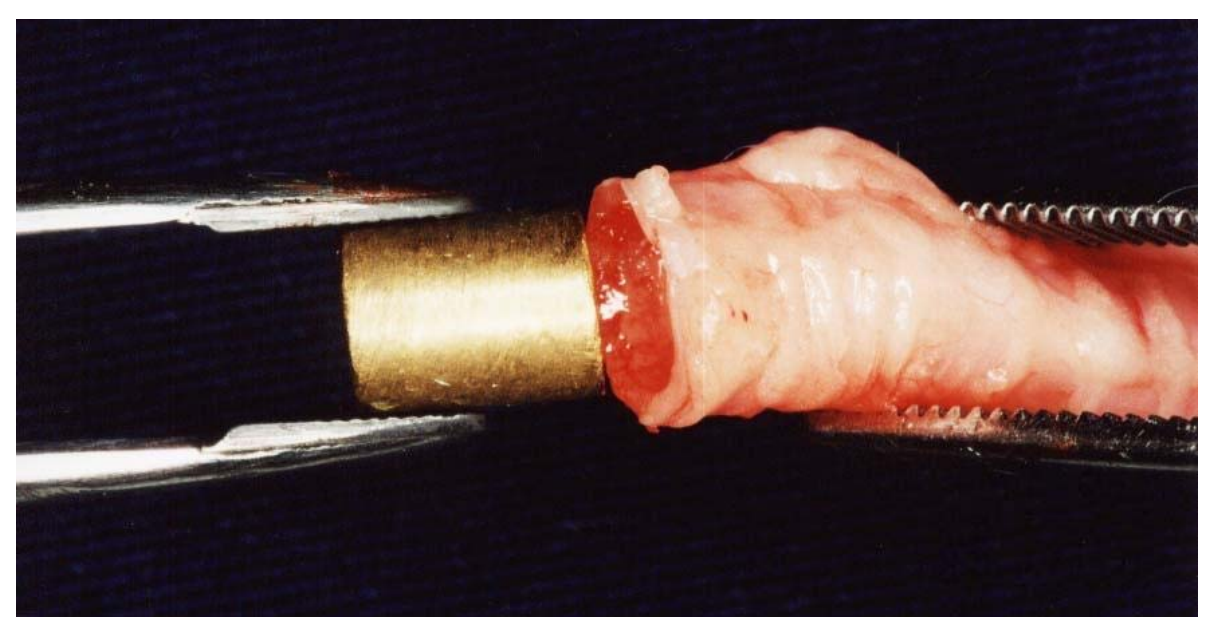

FIGURA 4 - Cilindros de cobre sendo conectados à luz da traquéia 
Um alinhamento prévio foi realizado antes do inicio de cada ensaio, a fim de assegurar que a carga fosse aplicada na direção longitudinal da traquéia. Foi utilizada na máquina universal de ensaio uma célula com capacidade de medição de carga de até $200 \mathrm{Kgf}$ $\left(\operatorname{KRATOS}^{\circledR}\right)$ e para as medidas das deformações foi utilizado um relógio comparador com a precisão de $0,01 \mathrm{~mm}$.

Foi aplicada uma pré-carga de $2 \mathrm{~N}$ e um tempo de acomodação de 60 segundos em todos os ensaios. A velocidade de aplicação da carga utilizada nos ensaios foi de $4,5 \mathrm{~mm}$ por minuto.

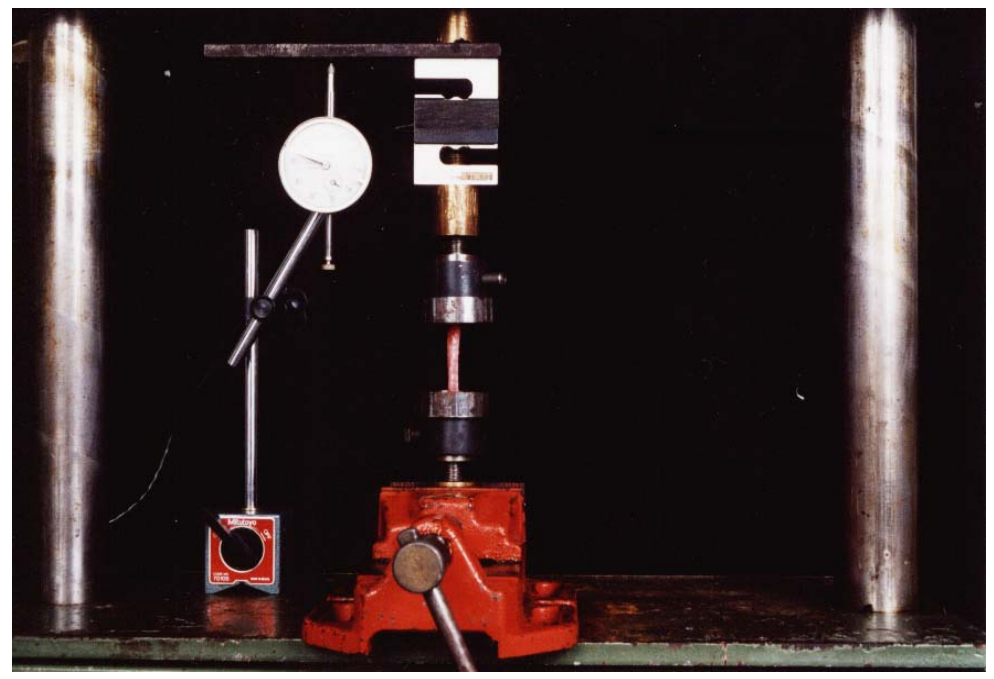

FIGURA 5 - Ensaio de tração da traquéia sendo realizado na Máquina Universal de Ensaios

Durante todo o ensaio foi realizado um gotejamento intermitente com soro fisiológico. Foram realizados registros da carga aplicada em intervalos de 0,5 $\mathrm{mm}$, até que houvesse a ruptura da traquéia.

\subsubsection{Gráfico Carga x Alongamento}

Com os valores dos alongamentos e cargas registradas, foi confeccionado os gráficos (carga $\mathrm{X}$ alongamento), onde o eixo das ordenadas representa os valores da carga 
aplicada $(\mathrm{N})$ e o eixo das abcissas representa os valores do alongamento da traquéia (X $10^{-3}$ m). Com os gráficos feitos foram determinados os valores da carga e alongamento no limite de proporcionalidade, carga e alongamento máximos, rigidez e energia absorvida na fase elástica.

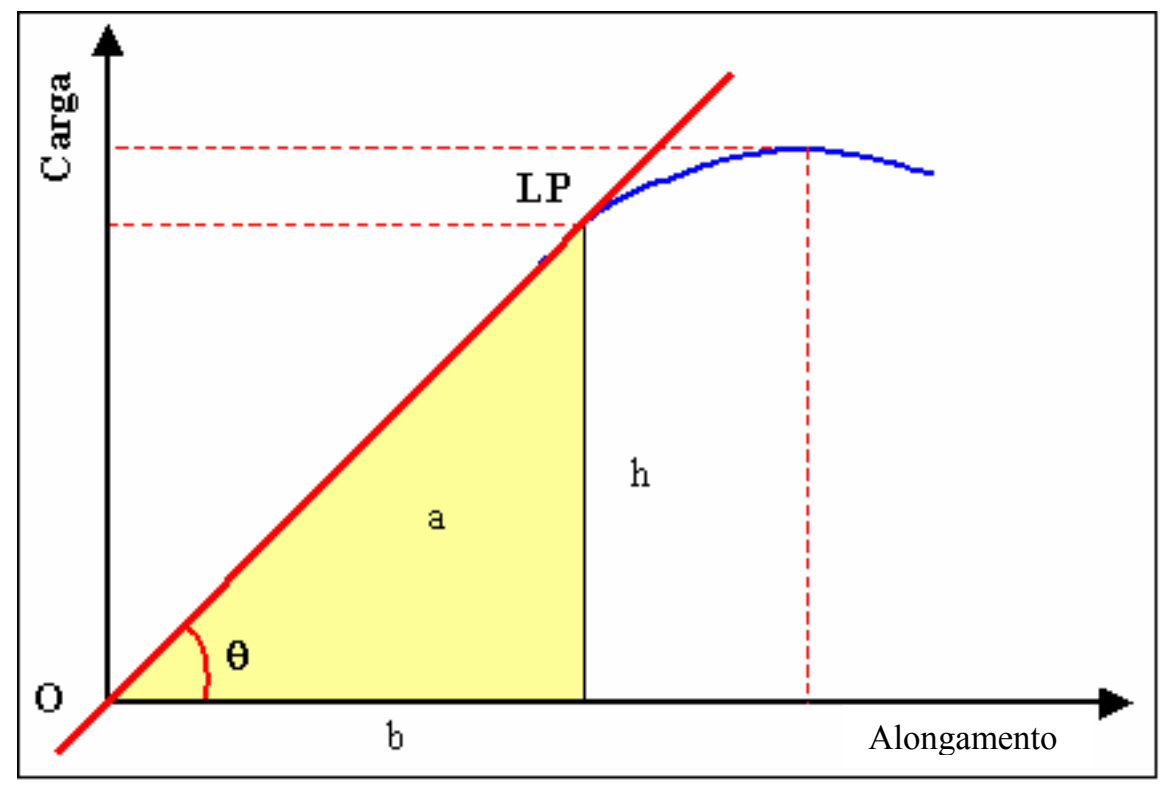

FIGURA 6 - Gráfico carga x alongamento, ilustrando o limite de proporcionalidade (LP), a reta que representa a inclinação da curva $(\theta)$, e o triângulo formado pela união dos pontos de início do ensaio e LP. A letra $\underline{h}$ representa a altura, $\underline{b}$ a base e $\underline{a} a$ área do referido triângulo.

\subsubsection{Limite de Proporcionalidade}

As cargas e deformações no limite de proporcionalidade de cada músculo foram obtidas tomando como referência o último ponto da reta de uma regressão linear, do gráfico (carga aplicada $\mathrm{x}$ alongamento) que caracteriza o ponto final da fase elástica. 


\subsubsection{Limite Máximo}

As cargas e alongamentos máximos foram os maiores valores obtidos de cada ensaio, antes que ocorresse a ruptura da traquéia.

\subsubsection{Energia Absorvida na Fase Elástica}

A energia absorvida na fase elástica foi calculada pela área abaixo de cada reta na fase elástica. A figura representada por esta área é um triângulo retângulo, portanto o cálculo é realizado do seguinte modo:

\subsubsection{Rigidez}

A rigidez foi obtida calculando-se a tangente do ângulo $\theta$ formado pela reta da fase elástica e a horizontal, representada pelo eixo das abcissas. O cateto oposto (h) representa o valor da carga aplicada e o cateto adjacente (b) o valor do alongamento.

\subsection{Estudo Histopatológico do Tecido Traqueal}

Após serem realizadas as medidas das traquéias, dois discos cartilaginosos foram retirados das mesmas, na região distal,e imersos em formolina a 10\% tamponada a fim de realizar estudos anatomopatológicos deste tecido. 
Os anéis cartilaginosos foram submetidos a cortes em micrótomo paralelos a seu maior eixo transversal. Para análise microscópica por patologista especializado foram empregadas as colorações de Tricrômio de Masson.

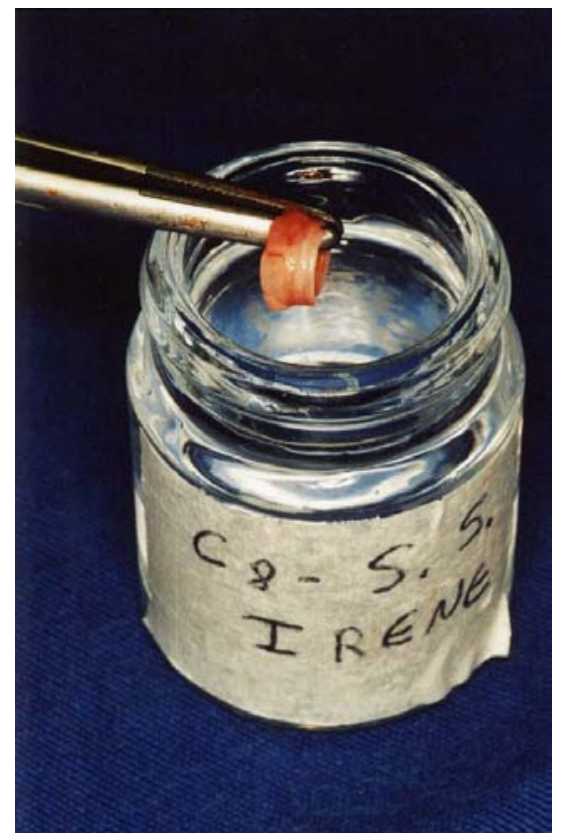

FIGURA 7 - Discos cartilaginosos sendo imerso em formol tamponado para posterior estudo histopatológico

\subsection{Análise Estatística}

Os resultados foram expressos na forma de médias e desvios-padrão. As comparações estatísticas entre os dois grupos foram realizadas empregando-se o teste t de Student. No processo de análise estatística os dados foram inicialmente tabulados em planilha do software Excel 97 (Microsoft) e os testes estatísticos realizados com o software Sigma Stat 2.0 (Jandel Scientific). Em todas as comparações foi fixado um nível para rejeição da hipótese de nulidade de $5 \%(\mathrm{p}<0,05)$. 


\section{RESULTADOS}

Foram estudadas 20 coelhas, das quais 10 compuseram o grupo controle (C) e 10 o grupo experimental (E). Para cada animal foi realizado um ensaio de tração não tendo sido excluído nenhum exame da pesquisa. 


\subsection{Peso dos Animais}

O valor médio do peso inicial dos animais do grupo controle foi de $3867 \pm 256 \mathrm{~g}$ e ao final do estudo o mesmo apresentou um peso médio de $3996 \pm$ $314 \mathrm{~g}$

No grupo experimental o peso inicial dos animais foi em média $3846 \pm$ $275 \mathrm{~g}$ e o final $3555 \pm 373 \mathrm{~g}$.

Os pesos médios dos grupos de animais não diferiram de maneira significante no momento do inicio do estudo. Após 21 dias de aplicação de metilprednisolona o grupo experimental apresentou um peso médio significativamente inferior ao do grupo controle (Figura 8).

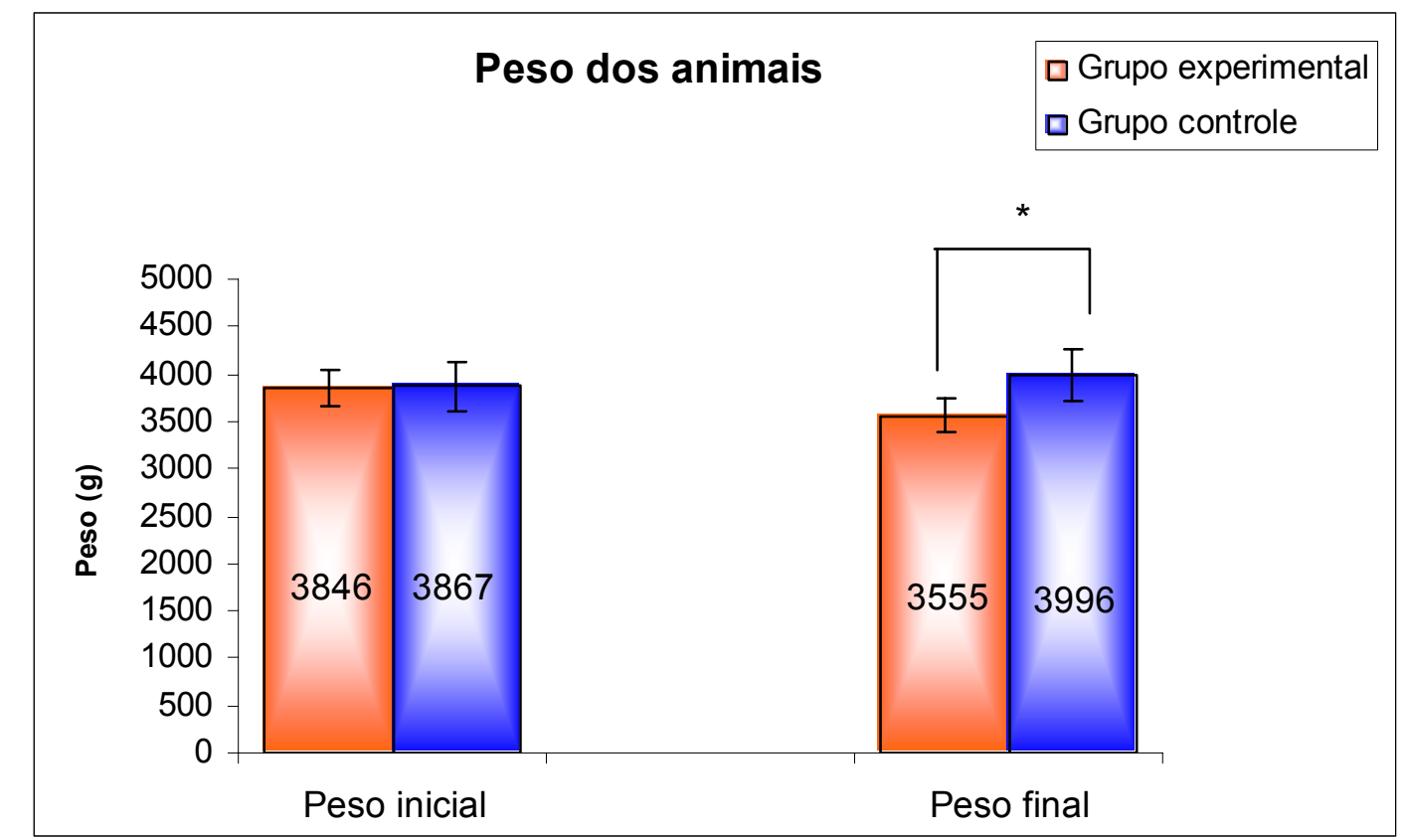

$(*=p<0,05)$ através do teste $t$ de Student

FIGURA 8 - Valores médios do peso inicial e final dos animais de ambos os grupos. 


\subsection{Consumo Alimentar}

A quantidade de ração consumida pelos animais foi verificada a cada 2 dias, e ao final de 21 dias, o peso médio de consumo alimentar para o grupo controle foi de 131,16 $\pm 21,79$ g e para o grupo experimental foi de $136,42 \pm 27,47$ g. Não houve diferença significativa na quantidade de alimentos consumida pelos animais quando comparado o grupo controle, com o grupo esperimental.

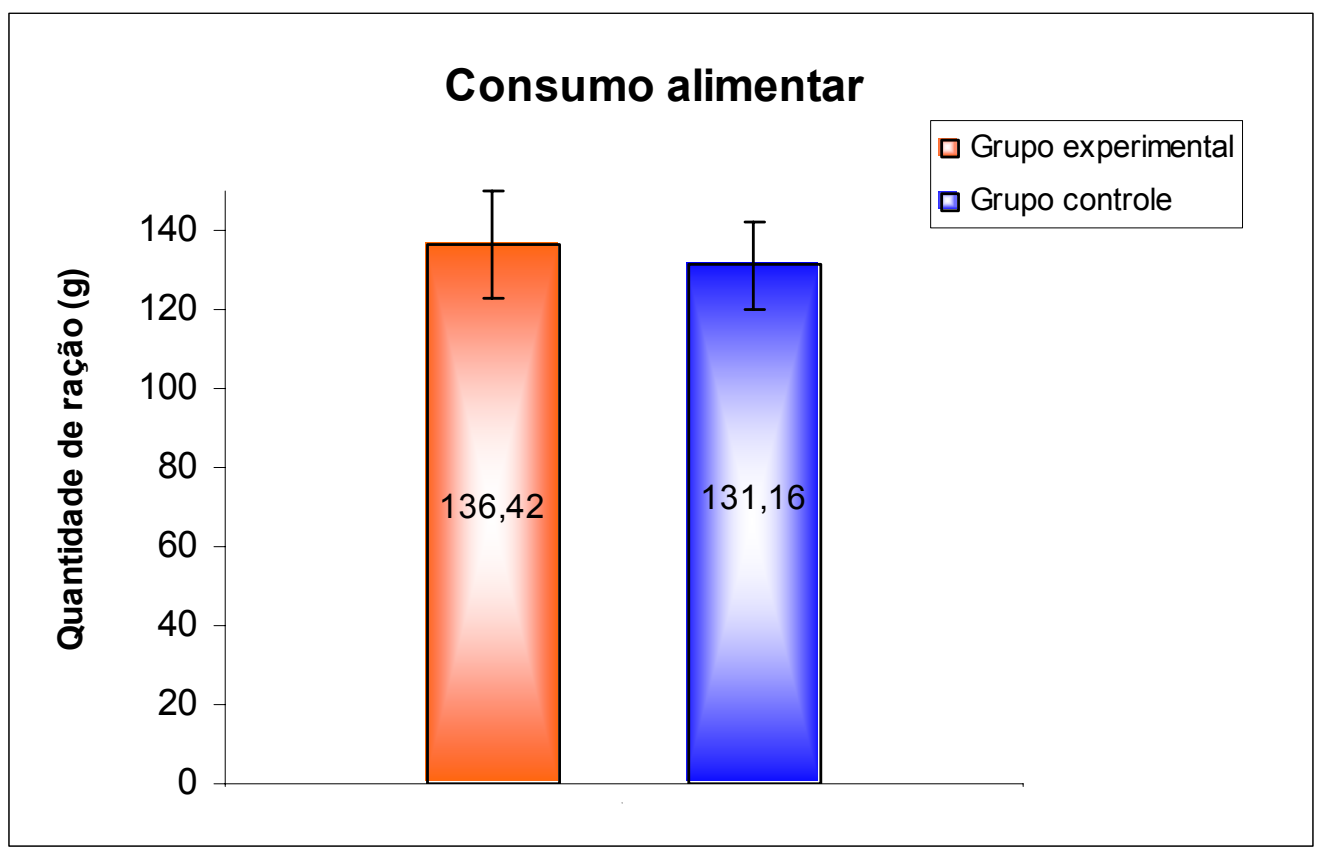

FIGURA 9 - Valores médios de consumo alimentar. 


\subsection{Quantidade de discos cartilaginosos}

Logo após a dissecção, as traquéias foram inspecionadas e em média elas mostraram $36 \pm 2$ discos cartilaginosos no grupo tratado com solução salina e $36 \pm 3$ discos cartilaginosos no grupo tratado com corticóide.

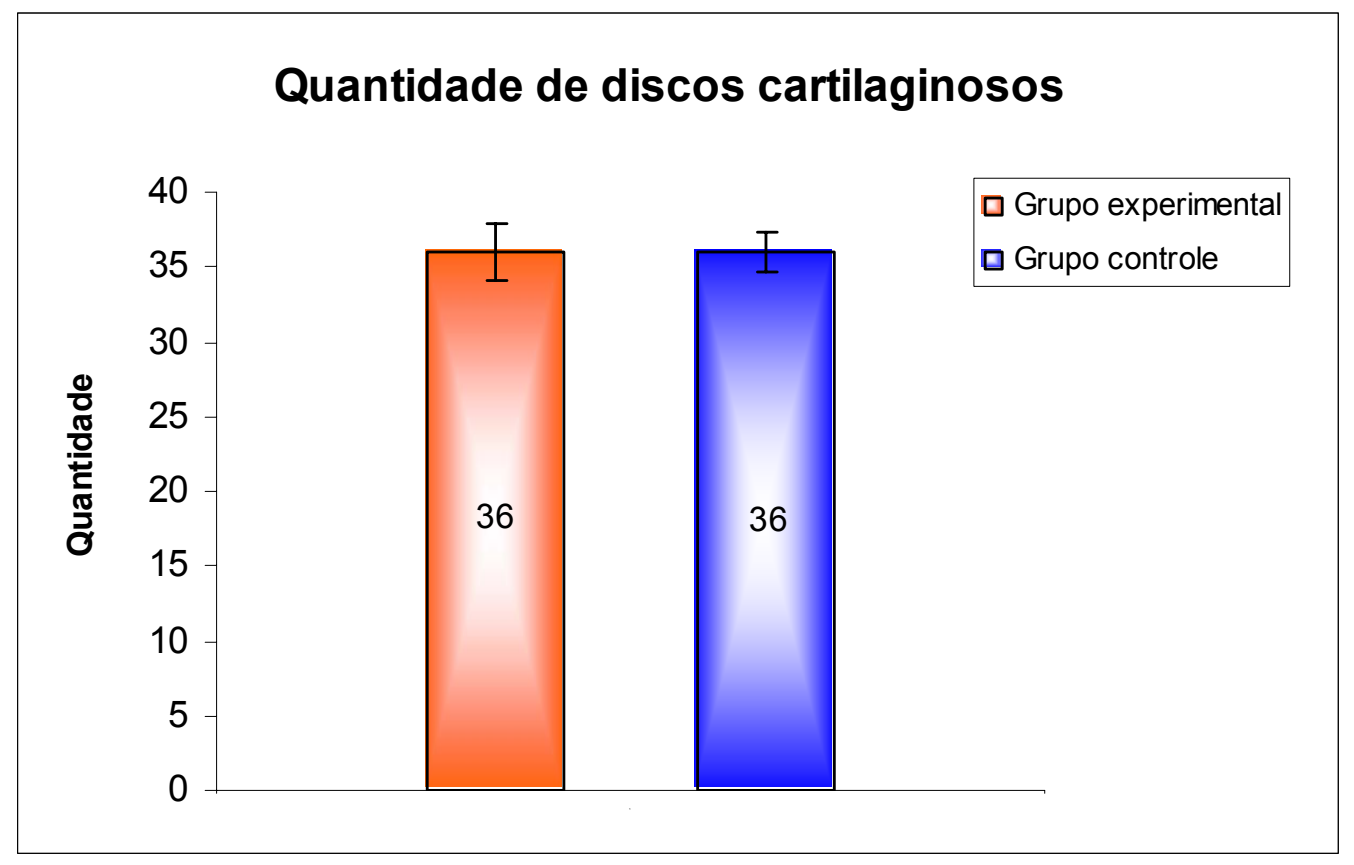

FIGURA 10 - Quantidade de discos cartilaginosos. 


\subsection{Peso das traquéias}

As traquéias foram pesadas e apresentaram um peso médio de $0,93 \pm 0,19 \mathrm{~g}$ no grupo experimental e $0,82 \pm 0,08$ g no grupo controle. Não houve diferenças significativas entre o peso da traquéia quando os grupos foram comparados entre sí.

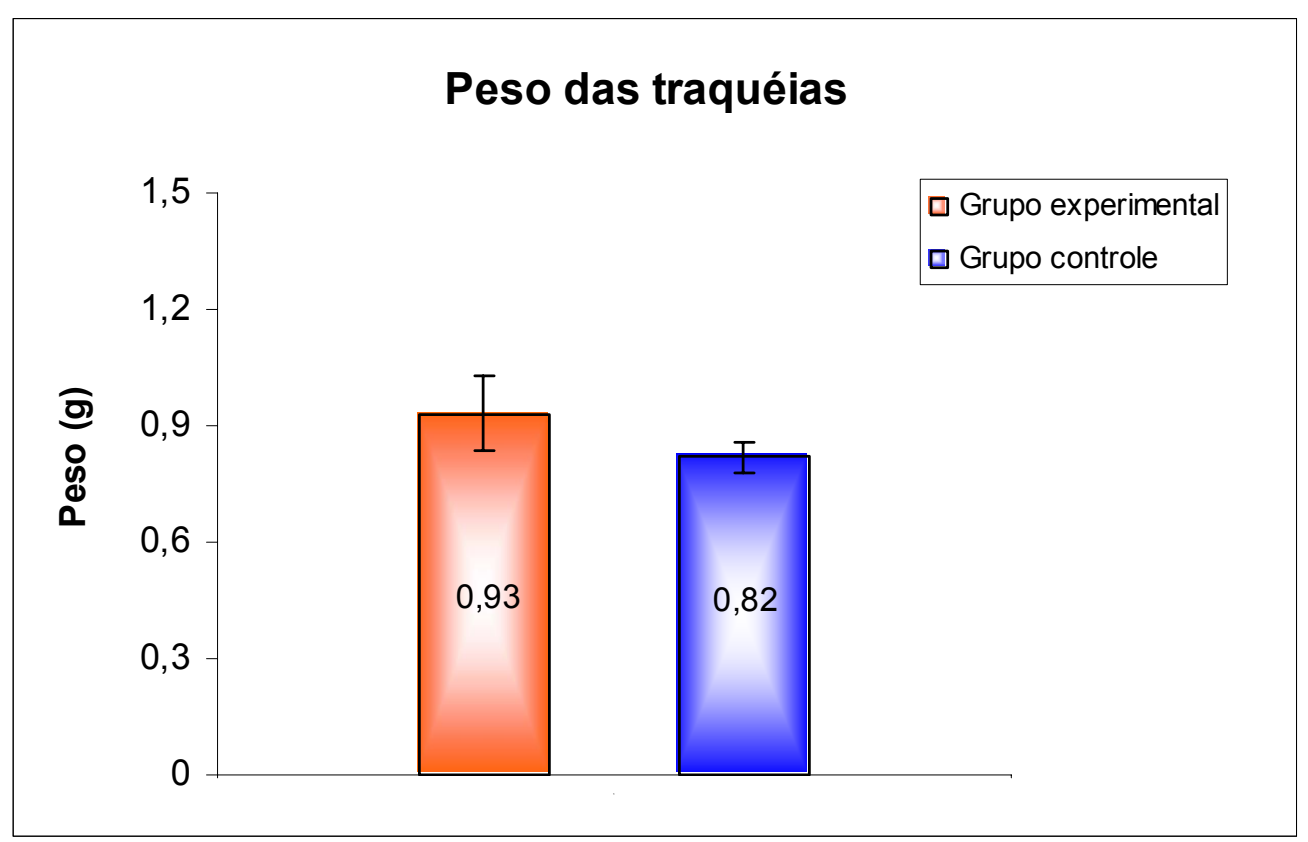

FIGURA 11 - Valores médios do peso da traquéia. 


\section{5 Área das traquéias}

O valor médio da área das secções transversais da traquéia do grupo controle foi de $16,19 \pm 7,14 \mathrm{~mm}^{2}$ para o grupo controle e de $16,24 \pm 6,53 \mathrm{~mm}^{2}$ para o grupo experimental. Não houve diferença estatística significante quando um grupo foi comparado ao outro.

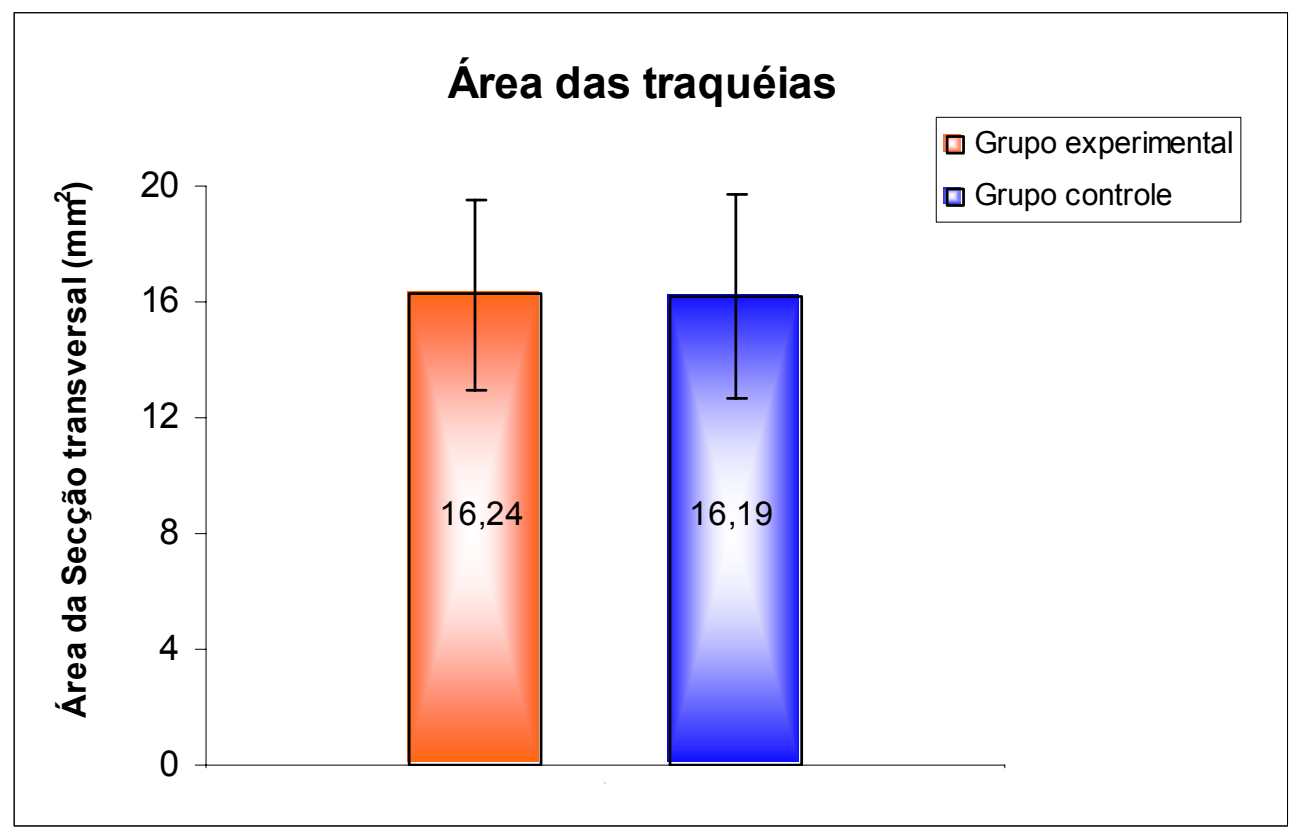

FIGURA 12 - Valores médios da área das traquéias. 


\subsection{Curvas Carga x Deformação}

Nas figuras 13 e 14, verifica-se os gráficos de carga e deformação que foram plotados para todos os animais do grupo controle e do grupo experimental.

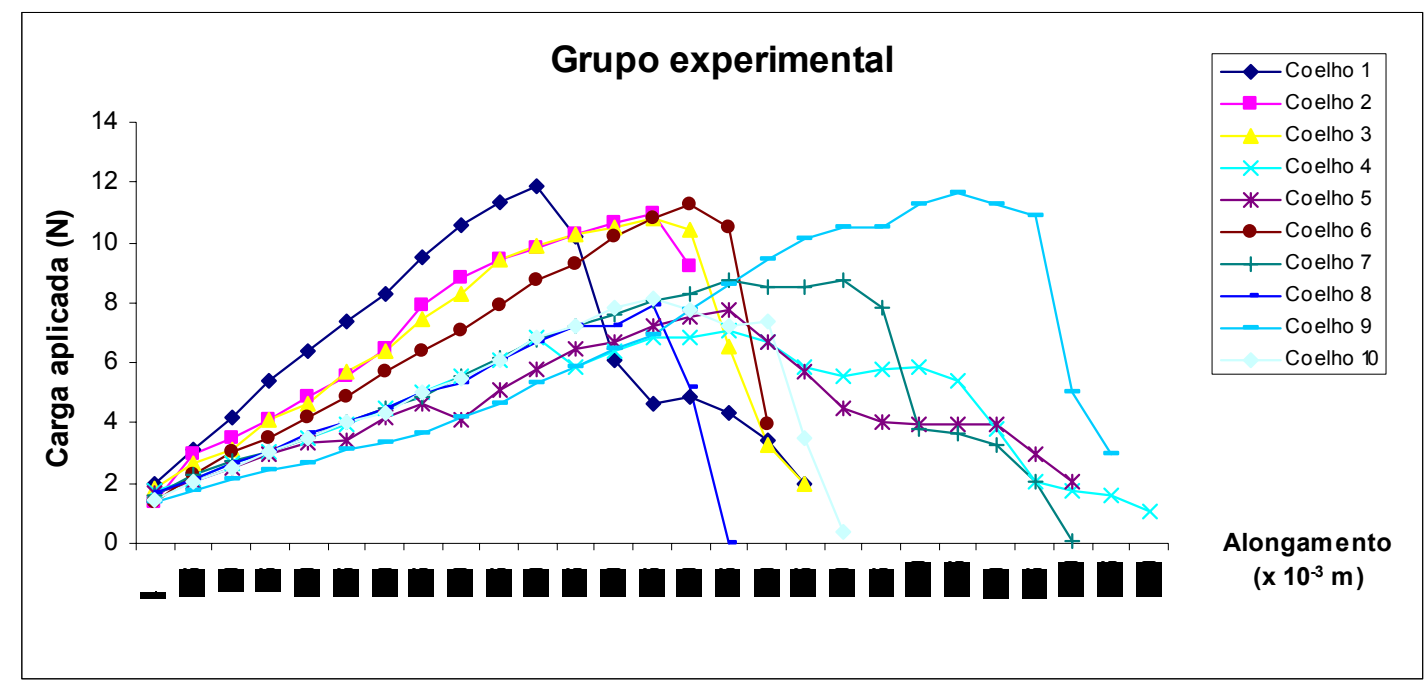

FIGURA 13 - Gráfico Carga x Alongamento das 10 traquéias das coelhas as quais foram administrados corticóide

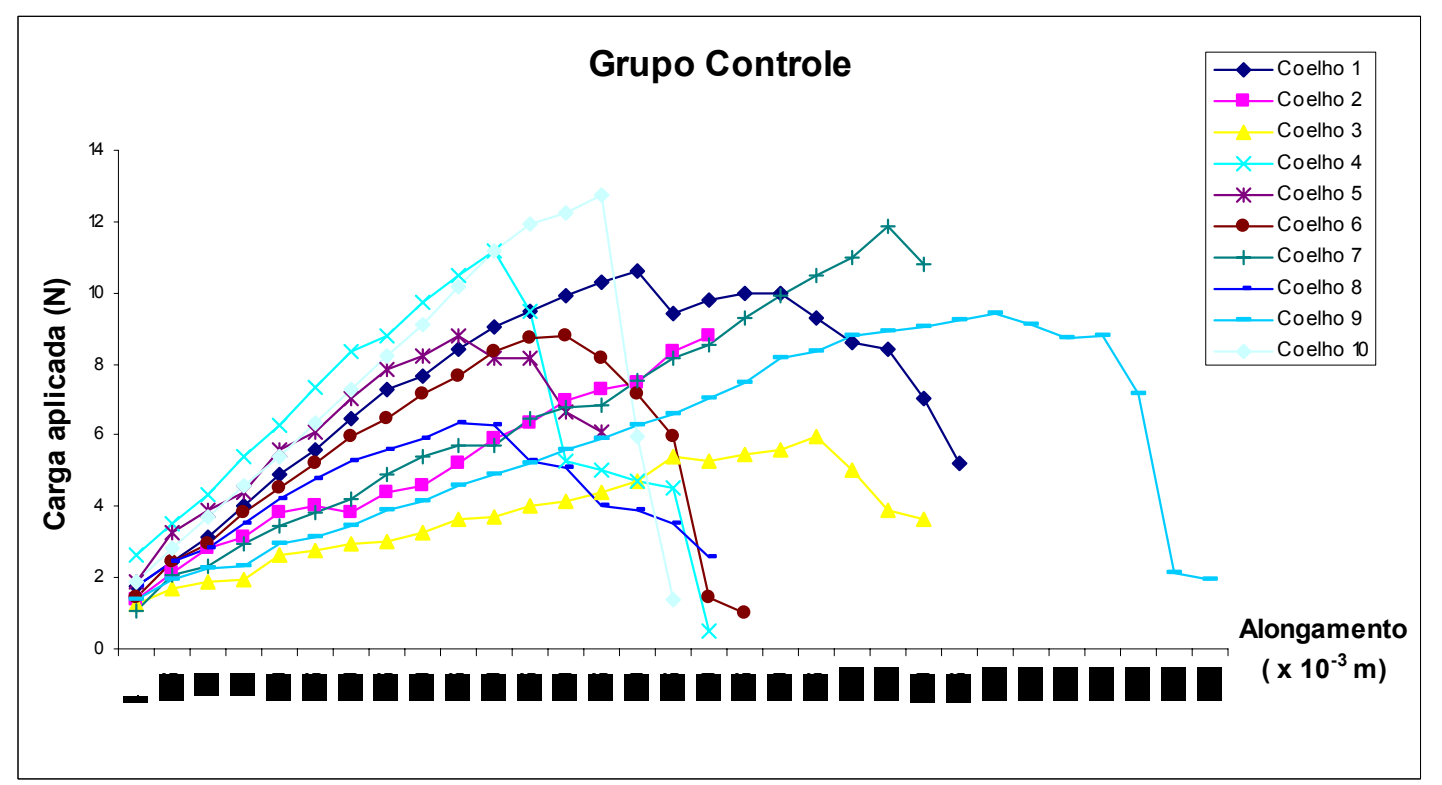

FIGURA 14 - Gráfico Carga x Alongamento das 10 traquéias das coelhas as quais foram administrados solução salina 


\subsection{Carga no Limite de Proporcionalidade}

O valor médio da carga no limite de proporcionalidade (LP) para as traquéias do grupo controle foi de 8,94 $\pm 1,68 \mathrm{~N}$ e para as traquéias do grupo experimental foi de $8,93 \pm 1,52 \mathrm{~N}$. A comparação entre os grupos mostrou que não houve diferenças significativas entre eles.

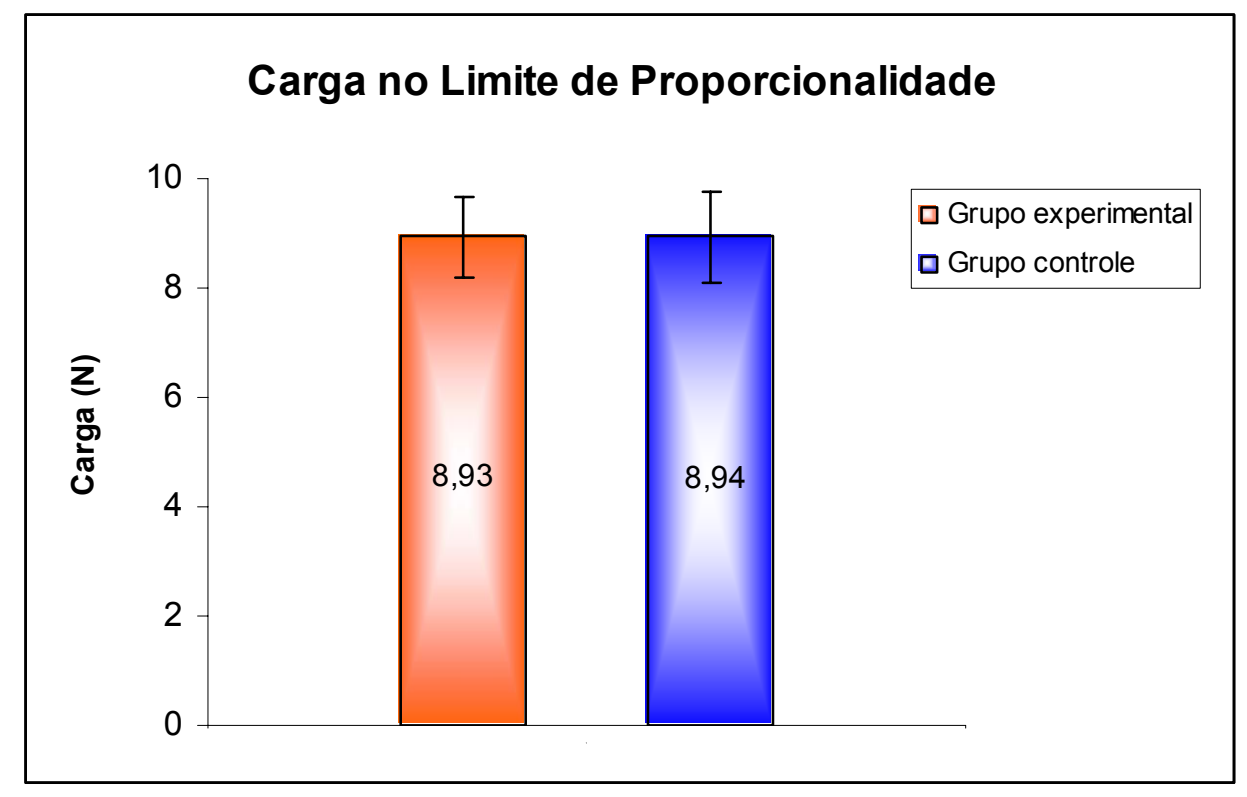

FIGURA 15 - Valores médios da carga aplicada no limite de proporcionalidade. 


\subsection{Carga Máxima}

A ruptura da traquéia ocorreu na sua região distal, próximo do vigésimo sétimo anel cartilaginoso, em 18 ensaios. Em apenas dois casos a ruptura ocorreu na região proximal da traquéia, entre o nono e décimo anel cartilaginoso, sendo que nestes dois casos as traquéias pertenciam ao grupo controle.

A carga máxima tolerada pelo tecido traqueal em média de $9,12 \pm 2,21 \mathrm{~N}$ para o grupo controle e de $9,57 \pm 1,90 \mathrm{~N}$ para o grupo experimental. Não houve diferenças significativas entre os grupos quando comparados estatísticamente.

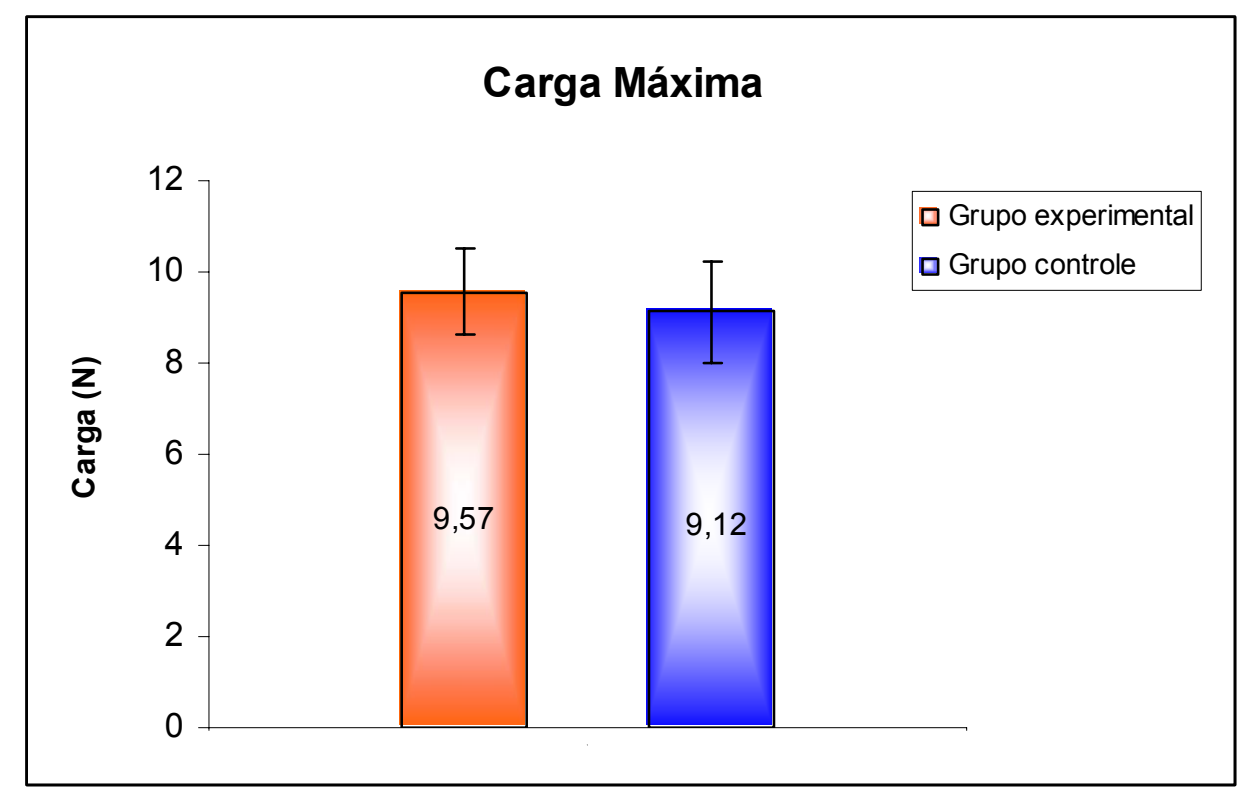

FIGURA 16 - Valores médios da carga máxima aplicada. 


\subsection{Alongamento no Limite de Proporcionalidade}

O valor médio do alongamento no limite de proporcionalidade das traquéias do grupo controle foi de $(6,83 \pm 2,08) \times 10^{-3} \mathrm{~m}$ e para as traquéias do grupo experimental foi de $(6,05 \pm 1,50) \times 10^{-3} \mathrm{~m}$. A comparação entre os dois grupos não mostrou diferença significativa entre eles.

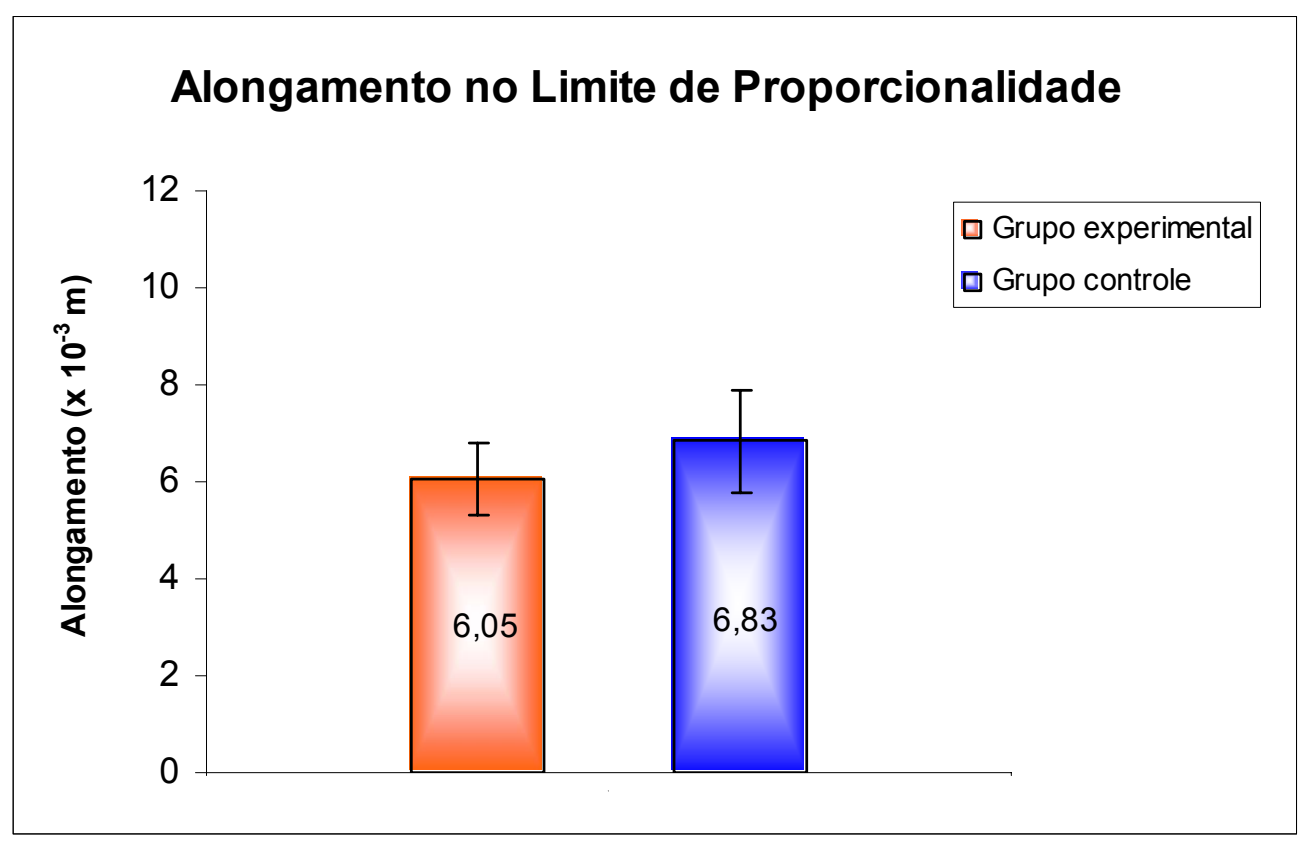

FIGURA 17 - Valores médios do alongamento no limite de proporcionalidade. 


\subsection{Alongamento Máximo}

O valor médio do alongamento máximo suportado pelo tecido traqueal antes de sua ruptura foi de $(7,44 \pm 2,60) \times 10^{-3} \mathrm{~m}$ no grupo controle e de $(6,85 \pm 1,55) \times 10^{-3} \mathrm{~m}$ no grupo experimental. A comparação entre os dois grupos mostrou que não houve diferença significativa entre eles.

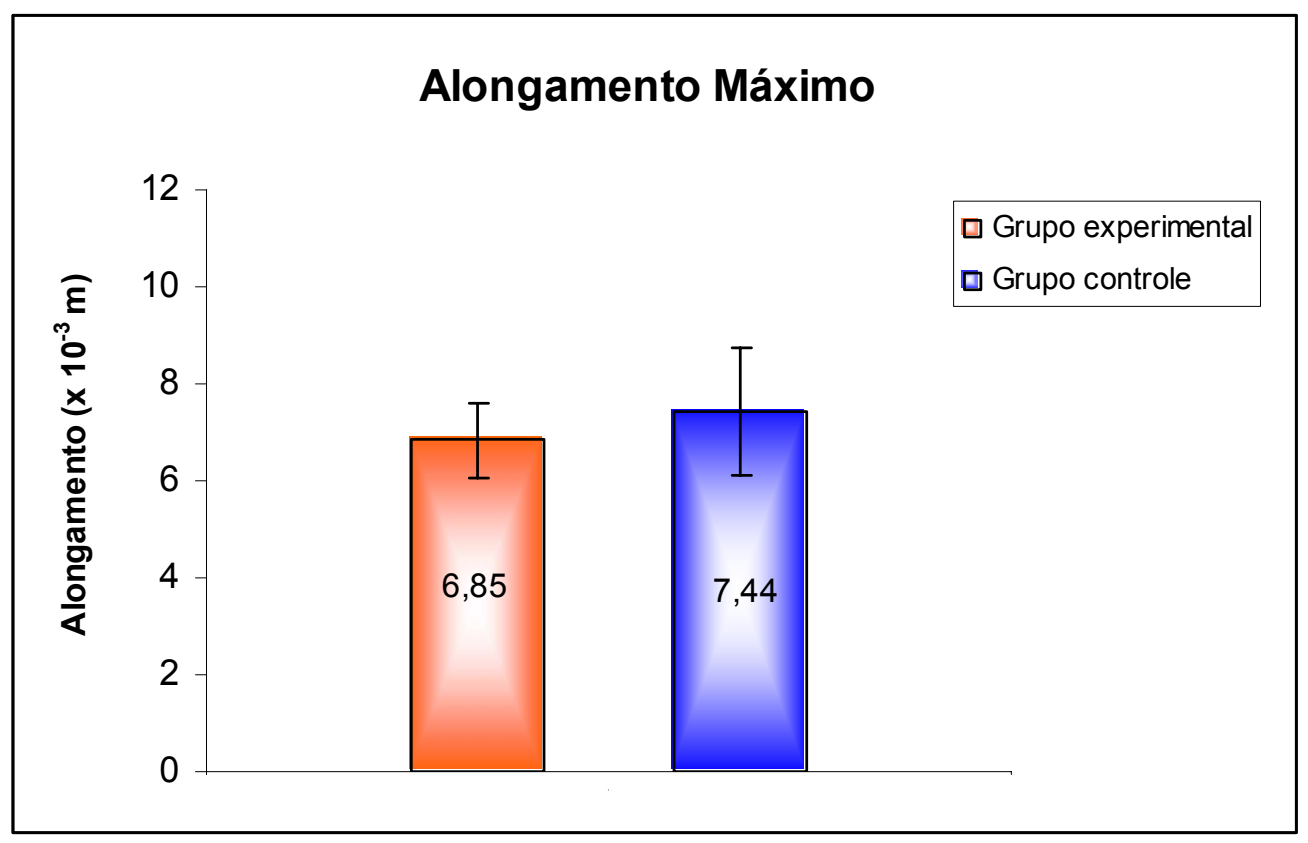

FIGURA 18 - Valores médios do alongamento máximo. 


\subsection{Energia Absorvida na Fase Elástica (Resiliência)}

O valor médio da energia absorvida na fase elástica foi, para as traquéias do grupo controle de $(28,70 \pm 14,43) \times 10^{-3} \mathrm{~J}$ e para as traquéias do grupo experimental foi de $(27,75 \pm 11,06) \times 10^{-3} \mathrm{~J}$. Não houve diferenças significativas quando os dois grupos foram comparados entre si.

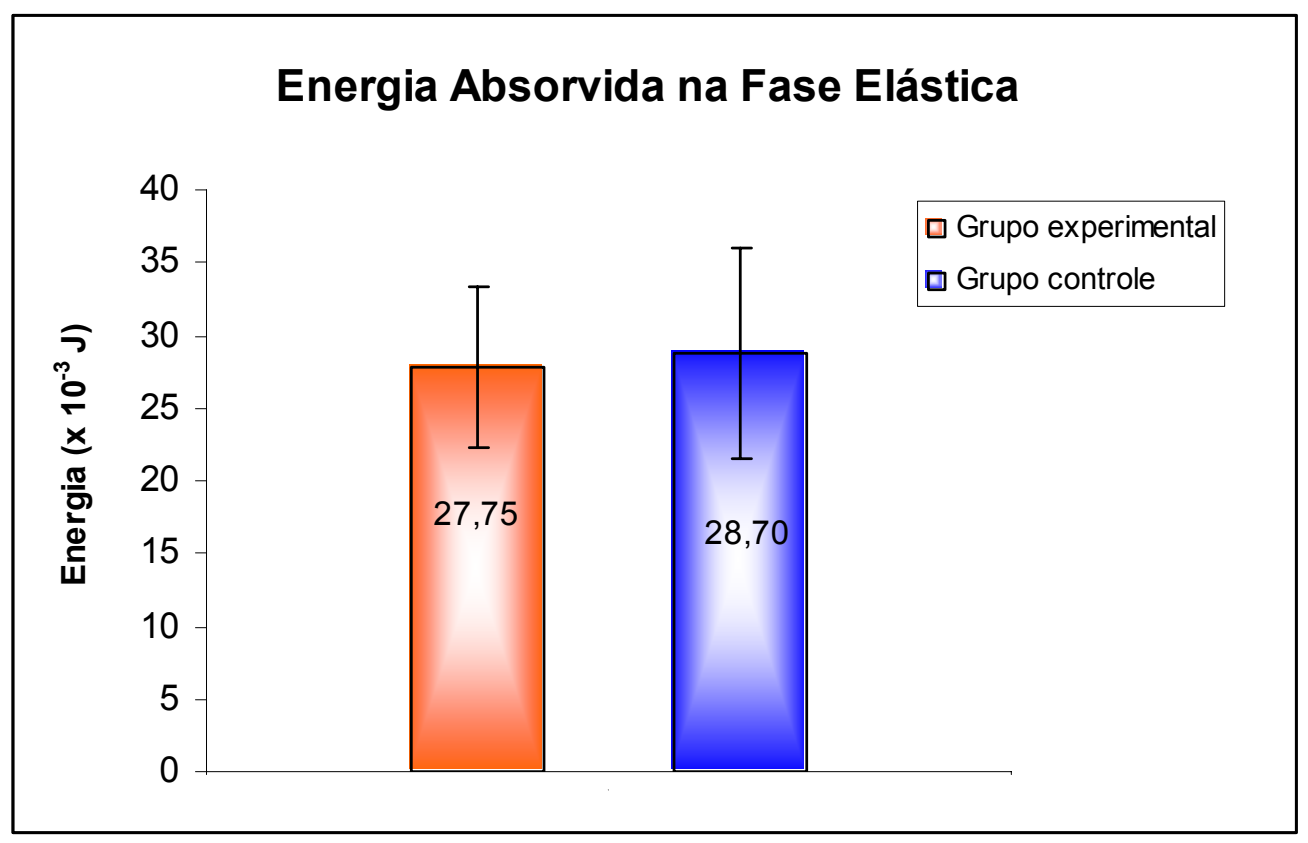

FIGURA 19 - Valores médios da energia absorvida na fase elástica. 


\subsection{Rigidez}

O valor médio da rigidez para as traquéias do grupo controle foi de $(1,08 \pm$ $0,41) \times 10^{3} \mathrm{~N} / \mathrm{m}$ e para as traquéias do grupo experimental foi de $(1,20 \pm 0,37) \times 10^{3} \mathrm{~N} / \mathrm{m}$. A comparação entre os dois grupos mostrou que não houve diferença significativa entre eles.

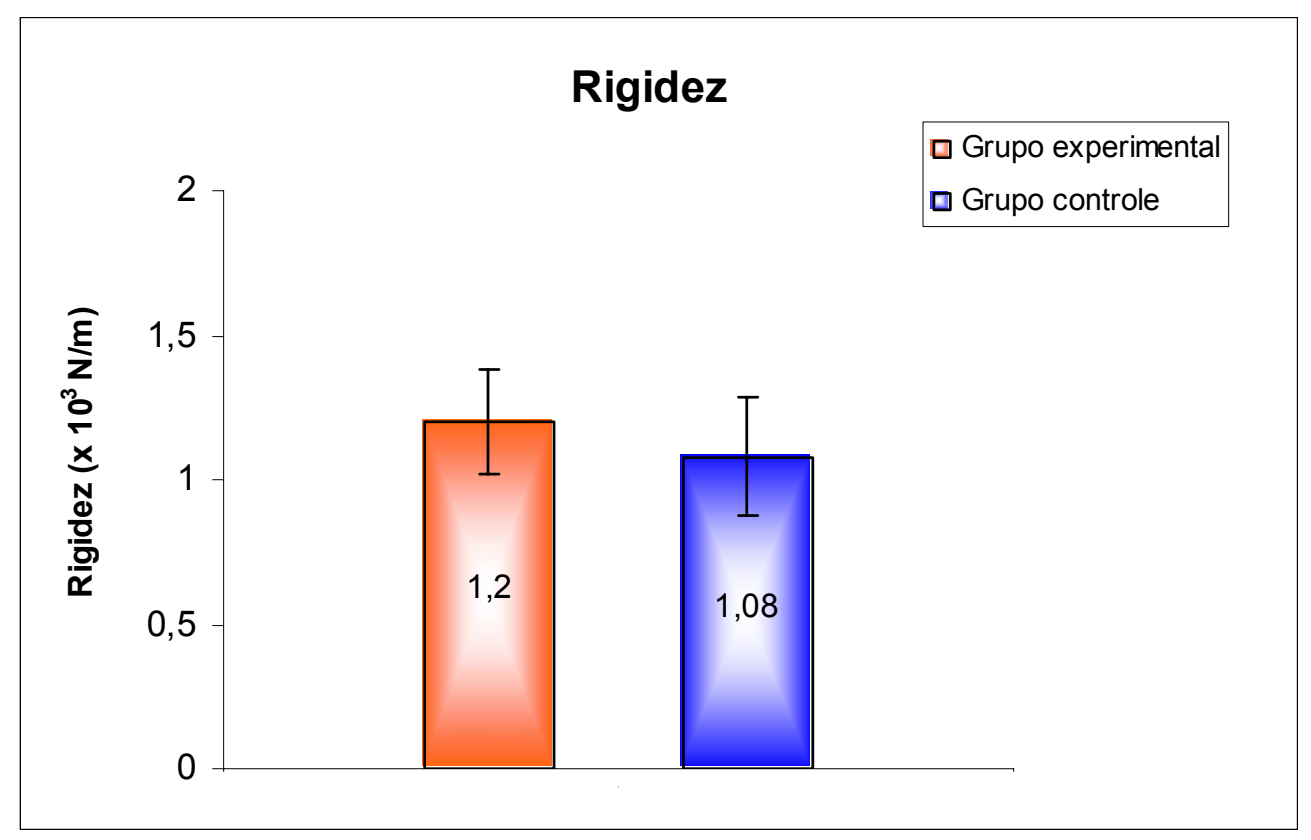

FIGURA 20 - Valores médios da rigidez. 


\subsection{Exame Histopatológico}

Numa análise qualitativa da morfologia das traquéias de ambos os grupos através de um aumento da imagem em 200 X não houve grandes alterações. Observou-se apenas um pequeno aumento da congestão dos vasos e do número de capilares ao nível da mucosa traqueal no grupo experimental (Figura 21).

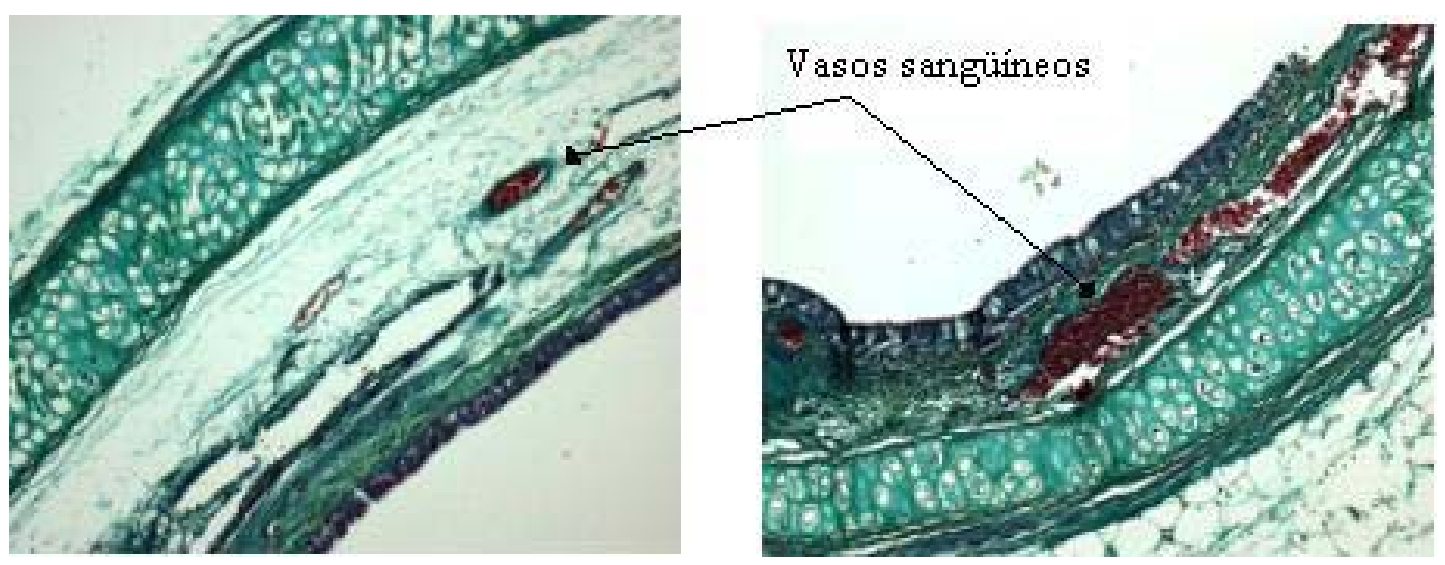

FIGURA 21 - Aspecto microscópico do tecido traquial estudado corado por tricrômio de Masson (aumento de 200 vezes). A esquerda foto do grupo controle e a direita foto do grupo experimental. 


\section{DISCUSSÃO}

A traquéia é elemento essencial do aparelho respiratório desempenhando inúmeras funções. Além do seu papel de via condutora de ar, seu epitélio de revestimento ciliado e a presença de reflexos nervosos são importantes mecanismos de defesa dos pulmões. Desta forma, a traquéia exibe peculiaridades anatômicas e fisiológicas próprias (WEST, 1990; RUPPEL, 2000). Apesar da importância da estrutura, são raros os estudos voltados à investigação das propriedades biomecânicas da traquéia.

A traquéia é um material anisotrópico, piezoelétrico e viscoelástico, o que a difere de alguns materiais ensaiados em engenharia. Apesar das diferenças entre os materiais biológicos e os materiais usados na engenharia, alguns métodos de análise de materiais podem ser adaptados para estudos de materiais biológicos.

Segundo SHIMANO \& SHIMANO (2000), materiais biológicos têm sido submetidos a ensaios de tração com sucesso no laboratório de Bioengenharia da Faculdade de Medicina de Ribeirão Preto. Ainda segundo estes autores, a velocidade de aplicação da carga nesses testes depende do tipo de material a ser ensaiado. Velocidades maiores são ideais para materiais mais elásticos, como músculos e ligamentos e velocidades menores para materiais mais rígidos, como os ossos. A importância da aplicação da pré-carga e do tempo de acomodação é para eliminar possíveis folgas existentes nas garras da máquina e para que haja uma padronização dos ensaios a serem realizados.

Os corticosteróides, também chamados de adrenocorticosteróides ou apenas corticóides, são hormônios de natureza esteroídica produzidos na porção cortical das 
glândulas adrenais. Tais hormônios compreendem três famílias: os glicocorticóides, os mineralocorticóides e os andrógenos. Os glicocorticóides são os principais hormônios do córtex adrenal, sendo o cortisol a sua forma mais comum. Embora a denominação glicocorticóide seja derivada do característico efeito dessas moléculas sobre o metabolismo dos carboidratos, essa classe de hormônios tem ação em praticamente todos os sistemas do organismo. Tanto os glicocorticóides naturais como seus derivados sintéticos são amplamente utilizados no tratamento de diversas moléstias devido principalmente às suas reconhecidas atividades anti-inflamatórias e imunossupressoras.

A produção do cortisol, pelo córtex da adrenal é regulada através do eixo hipotálamo-hipófise-adrenal. Normalmente, o fator liberador de corticotropina (CRF), um neuro-hormônio secretado pelo hipotálamo, estimula a liberação de ACTH (hormônio adreno-corticotrópico) pela hipófise anterior que, por seu lado, estimula a produção de cortisol pela glândula adrenal (GILMAN, 1996). Através de um mecanismo de feedback negativo, a produção de $\mathrm{ACTH}$, também é regulada pelo cortisol, do seguinte modo: concentrações elevadas de cortisol ou de um glicocorticóide sintético resultam na redução da secreção do ACTH, que então deixa de estimular a adrenal. Por sua vez, a liberação de CRF é inibida pelos níveis de glicocorticóides e, em menor grau, de corticotropina no sangue, sendo influenciado pelo influxo proveniente do sistema nervoso central.

O interesse pelo estudo da corticoterapia iniciou-se em 1855 quando Addison descreveu a síndrome clínica resultante de uma doença que derivava da disfunção das glândulas adrenais. Baseado nas observações de Addison, em 1856, Brown-Séquard desenvolveu experimentos pioneiros sobre o efeito da adrenalectomia em animais de laboratório. Porém, somente em 1943 a estrutura dos esteróides foi descoberta a partir de extratos de adrenal, o que possibilitou a síntese do cortisol em 1946 (GILMAN, 1996).

Em 1948, Hench) utilizou pela primeira vez o cortisol na artrite reumatóide e relatou então seus efeitos dramáticos. $\mathrm{Na}$ mesma época, entretanto, foi prontamente 
reconhecida a ocorrência de uma série de efeitos colaterais associada a esse tipo de terapia. Hoje sabemos que entre as reações indesejáveis do uso crônico dos glicocorticóides destacam-se a hiperglicemia, osteoporose, supressão da resposta a infecção, alterações do equilíbrio hidroeletrolítico, atrofia muscular, fraqueza, inibição do crescimento em crianças, cataratas, entre outros (GILMAN, 1996; RANG et al. 2001).

Em 1950 a hidrocortisona foi sintetizada, mostrando-se ser mais ativa do que o cortisol, porém, apresentando os mesmos efeitos colaterais desfavoráveis. Já, em 1954, havia intensa procura por corticosteróides de maior potência e com menos efeitos indesejáveis, o que levou a modificação do cortisol e da hidrocortisol com êxito (GILMAN, 1996). Esta modificação resultou na síntese da prednisolona e prednisona que atualmente são utilizadas em grande escala na prática clínica.

Em meio a diversos outros efeitos metabólicos, o excesso de glicocorticóides durante períodos prolongados, seja secundário a terapia medicamentosa, seja decorrente de hipercorticismo endógeno, tende a causar diminuição da musculatura esquelética através de mecanismos ainda não completamente conhecidos (GILMAN, 1996). Além disso, os glicocorticóides também inibem a síntese de fibras de tecido conjuntivo, podendo interferir negativamente no processo de cicatrização das feridas (JUNQUEIRA \& CARNEIRO, 1999). O tratamento com glicocorticóides pode levar igualmente a diminuição da densidade óssea (STAA et al., 2000; REID et al., 2000; WATERS et al., 2000; HANLEY et al., 2000; SELBY et al., 2000; JOY et al, 2000; CRANNEY et al., 2000; NEGRI et al., 1999; SAMBROOK, 2000).

A traquéia é constituída por discos de cartilagem hialina, pericôndrio, feixes musculares lisos e tecido conjuntivo fibroso e frouxo. Como tais tecidos, em particular o fibroso e o muscular, podem sofrer ação do uso de glicocorticóides em altas doses, desenvolvemos um projeto de pesquisa voltado a caracterização de possíveis alterações das propriedades biomecânicas da traquéia em animais submetidos a terapia com altas doses de metilprednisolona. 
Embora todos os glicocorticóides apresentem no geral um perfil de efeitos colaterais semelhantes, existem diferenças sutis, bem conhecidas e clinicamente importantes, entre os diferentes tipos de fármacos. Além disso, cada glicocorticóide apresenta uma estrutura molecular própria e por isso, um perfil específico de efeitos biológicos e farmacológicos, em relação as suas características farmacocinéticas e farmacodinâmicas.

A metilprednisolona administrada de modo sistêmico apresenta em relação à hidrocortisona uma potência antiinflamatória cinco vezes maior, retenção de sódio vinte vezes menor, e tem duração intermediária, ou seja, meia vida biológica de 12 a 36 horas, enquanto o cortisol apresenta meia vida biológica curta, ou seja, de 8 a 12 horas (GILMAN, 1996).

Nesta pesquisa optamos pelo uso da metilprednisolona, devido ao fato dessa droga ser muito utilizada na prática clínica, geralmente em altas doses e em situações de risco como, por exemplo, o tratamento de episódios de rejeição de enxertos, broncoespasmos intensos, comprometimento de órgãos nobres por doenças do colágeno, como o lupus eritematoso e vasculites sistêmicas, etc. Além disso, um aspecto particularmente importante da farmacodinâmica da metilprednisolona é a sua ação pronunciada na diminuição dos processos inflamatórios dos tecidos pulmonares e das vias aéreas (PAVLOVIC, 1998). Dessa forma, essa medicação acaba encontrando grande emprego em pacientes pneumopatas graves, justamente os indivíduos nos quais uma hipotética disfunção traqueal relacionada ao uso dos esteróides seria mais prejudicial.

Utilizamos nesta pesquisa coelhas adultas da raça Nova Zelândia, pois baseando-se no estudo comparativo da anatomia de coelhos e de humanos, conclui-se que as estruturas formadoras da traquéia, em ambos as espécies são as mesmas, ou seja, tais estruturas são compostas por discos de cartilagem hialina, interligadas entre si por tecido conjuntivo fibroso e frouxo. Animais de pequeno porte, como o rato, também apresentam estruturas traqueais semelhantes a do humano. No entanto, o pequeno comprimento 
longitudinal de suas traquéias, dificultaria a fixação das mesmas na Máquina Universal de Ensaio. Por outro lado, animais maiores, tais como cães, carneiros e porcos, embora fornecessem traquéias maiores para os ensaios, cursariam com dificuldades para manutenção no biotério devido ao limitado espaço físico do mesmo.

Em nosso trabalho foi feita ainda opção por fêmeas, devido elas atingirem tamanho superior ao dos machos, uma vez que muitas delas são mantidas como procriadoras, e assim alcançam uma idade média maior do que a dos machos. Dessa forma, asseguramos que seriam utilizados na pesquisa animais adultos e com traquéias de comprimento longo o suficiente para adaptação adequada na Máquina Universal de Ensaios.

A opção por animais adultos deveu-se ainda ao fato de experimentos realizados por HAMAIDE et al (1998) terem demonstrado em cães que a idade dos animais pode interferir nas propriedades biomecânicas e bioquímicas da traquéia.

Sendo assim, as traquéias de coelhas adultas foram consideradas as mais adequadas para a presente pesquisa, necessitando apenas, devido a sua estrutura tubular, que se confeccionassem pequenos cilindros para adaptá-las à máquina universal de ensaios.

Um cuidado tomado em relação à administração da medicação foi relacionado ao horário de sua aplicação. Os animais receberam as injeções subcutâneas sempre no período da manhã, a fim de adequar a terapêutica à fisiologia normal, pois a concentração de corticóides endógenos no sangue apresenta-se elevada na manhã e reduzida à noite (RANG et al, 2001).

A dose de esteróide a ser aplicada diariamente nos animais foi estipulada buscando-se um equilíbrio entre uma quantidade de droga capaz de induzir alterações antiinflamatórias acentuadas e efeitos colaterais que não impedissem a sobrevida prolongada dos animais. Dessa forma, através de estudos preliminares ficou claro que o uso de doses de metilprednisolona superiores a $2 \mathrm{mg} / \mathrm{kg} / \mathrm{dia}$ e tratamentos com essa dose além de três semanas eram muito mal toleradas pelos animais, cursando com acentuada perda de peso e 
um número substancial de óbitos, na maioria das vezes devido a complicações infecciosas, particularmente pneumonias. A dose escolhida de $2 \mathrm{mg} / \mathrm{kg} / \mathrm{dia}$ de metilprednisolona sabidamente leva a bloqueio da resposta inflamatória e imune em humanos.

No presente estudo as traquéias foram colocadas na Máquina Universal de Ensaios de tal modo que a tração foi aplicada ao longo do seu maior eixo. As traquéias foram presas ao sistema através de garras especiais que permitiam a manutenção da luz e estrutura tubular traqueal intactas. Neste trabalho foi utilizada uma pré-carga de $2 \mathrm{~N}$, um tempo de acomodação de 60 segundos e uma velocidade de aplicação de carga de 4,5 mm por minuto, pois após alguns testes preliminares julgou-se que esta fosse uma padronização de ensaio ideal para traquéias de coelhos.

Segundo HAMILL \& KNUTZEN (1999), a análise de curvas cargadeformação pode ser utilizada para determinar se um material é duro, maleável, frágil, forte ou fraco. Um material duro responderá com mínima deformação ao aumento de carga. Quando o material falha ao final da fase elástica, como o que acontece por exemplo com o vidro, ele é considerado um material frágil. Na presente pesquisa, observou-se que a traquéia é considerada um material maleável, pois não apresenta linearidade na curva carga $\mathrm{x}$ deformação; alongando-se e deformando-se muito na fase elástica.

No presente estudo os animais não diferiram quanto ao seu peso inicial indicando que se tratava de grupos comparáveis. Entretanto, ao final do estudo o grupo tratado com corticóide apresentou um peso significantemente inferior ao do grupo tratado com placebo. De fato, enquanto os animais do grupo tratado com solução salina ganharam peso, o grupo tratado com metilprednisona mostrou comportamento oposto. Tal fato já foi encontrado previamente em inúmeros estudos animais realizados com a administração de glicocorticóides em altas doses e pode ser explicado pelos efeitos catabólicos da droga sobretudo sobre os grupos musculares. Os efeitos dos glicocorticóides no metabolismo de carboidratos e proteínas é um processo que envolve a estimulação do fígado para formação 
de glicose a partir de aminoácidos e glicerol e também pela estimulação da deposição de glicose como glicogênio hepático. Na periferia, os glicocorticóides diminuem a utilização de glicose, aumentam a clivagem protéica e ativam a lipólise, gerando, por conseguinte, aminoácidos e glicerol para a gliconeogênese. Estes efeitos periféricos estão associados a inúmeras ações catabólicas, inclusive atrofia do tecido linfóide e massa muscular diminuída (GILMAN, 1996).

Com respeito à distribuição de lipídios, em humanos há um aumento de tecido adiposo na região dorsal do pescoço, face e área clavicular, juntamente com uma perda de tecido adiposo nas extremidades (GILMAN, 1996). No entanto, essa desproporção na distribuição de tecido adiposo não foi observada nos animais no decorrer da pesquisa.

Glicocorticóides podem levar à retenção de liquido com conseqüente ganho de peso. Porém, a metilprednisolona em particular apresenta apenas mínimos efeitos mineralocorticóides. Dessa forma, a perda de peso agora observada deve ser atribuída principalmente a perda de massa muscular. Um outro mecanismo pelo qual os animais poderiam perder peso seria relacionado ao surgimento de distúrbios alimentares. Embora o uso de glicocorticóides curse com aumento do apetite, tais drogas quando usadas em altas doses e por longo tempo podem levar igualmente ao desenvolvimento de gastrites e úlceras pépticas, fatores que poderiam dificultar a digestão e a absorção de nutrientes. Entretanto, a evidência de que dispomos neste estudo não aponta nessa direção, uma vez que o controle de ingesta de ração realizado em dias alternados mostrou que a quantidade média de ração ingerida entre os dois grupos foi semelhante.

Embora o grupo de animais tratado com metilprednisolona tenha apresentado um peso total inferior ao do grupo controle, o peso e as dimensões médias da traquéia não diferiram entre os grupos. Este achado sugere que a traquéia não tenha sofrido efeitos catabólicos significantes induzidos pelo glicocorticóide. 
Os efeitos da administração de esteróides sobre os aspectos estruturais e histológicos da traquéia têm sido alvo de poucos estudos.

PAVLOVIC et al. (1998) investigaram o efeito de sete dias de tratamento com triamcinolona em doses de $1,2 \mathrm{mg} / \mathrm{kg} / \mathrm{dia}$ na estrutura epitelial e musculatura lisa traqueal de ratos. Os animais tratados com o esteróide apresentaram perda de peso acentuada em comparação aos grupos controles, que não pode ser explicada totalmente por alterações da ingestão alimentar. Os autores observaram que a administração do corticóide associou-se à redução do número de células epiteliais da mucosa e da área de secção transversal da musculatura lisa traqueal. Também foi evidenciado acentuado prejuízo da capacidade da traquéia gerar tensões máximas secundariamente à contração da musculatura lisa estimulada por carbacol. As alterações funcionais de contratilidade foram atribuídas à atrofia da musculatura lisa traqueal, secundária ao uso da droga.

LIMA et al (1981) avaliaram os efeitos da terapia imunossupressora em baixas doses sobre a cicatrização bronquial pós-transplante pulmonar em cães. Eles avaliaram 28 cães, dividindo-os em dois grupos. No grupo I (controle) foram avaliados 15 cães e no grupo II foram avaliados 13 cães. No grupo I não foram administrados imunossupressores, porém, o grupo II recebeu metilpredinisolona (2 $\mathrm{mg} / \mathrm{Kg} / \mathrm{dia})$ e azatioprina $(1,5 \mathrm{mg} / \mathrm{Kg} / \mathrm{dia})$ até o dia do sacrifício. Em intervalos de 4, 9, 16 e 23 dias foram retirados fragmentos de $1 \mathrm{~cm}$ de largura da pele e da anastomose brônquica, que eram então submetidos a ensaioi mecânico de estiramento até a ruptura.

Os autores observaram que a resistência à ruptura das anastomoses brônquicas foram semelhantes entre os grupos nos dias 4 e 9 . No dia 23 o grupo tratado com imunosupressores mostrou uma resistência à ruptura significantemente inferior ao do grupo controle. $\mathrm{O}$ aspecto histológico no dia 9 foi similar entre os dois grupos, com extensa inflamação e pobre deposição de colágeno. Após 23 dias houve moderada inflamação e boa deposição de colágeno em dois-terços dos animais do grupo controle e em metade dos animais imunossuprimidos. Os autores concluíram que o uso crônico de metilprednisolona 
associada à azatioprina pode induzir quedas significantes da resistência das anastomoses brônquicas.

SMITH et al (1994) estudaram os efeitos da metilprednisolona, aplicada isoladamente ou associada à ciclosporina na angiogênese da traquéia de ratazanas, em um modelo de enxerto heterotópico de traquéia. Muito embora a metilprednisolona tenha contribuído para acelerar a regeneração epitelial, ela não influenciou no grau da vascularização da mucosa traqueal avaliada por morfometria. Entretanto JADCZUC (1998), investigando uma técnica de neovascularização e reimplante traqueal em porcos, mostrou que o uso de hidrocortisona em altas doses cursou com significante elevação do número de capilares da mucosa e menor número de estenoses traqueais e óbitos.

$\mathrm{O}$ presente estudo procurou investigar as conseqüências do uso de metilprednisolona, em altas doses e por um período longo de tempo, sobre algumas propriedades biomecânicas da traquéia de coelhos. O assunto é de relevância diante dos efeitos potenciais do glicocorticóide sobre as cartilagens, tecido conjuntivo e musculatura lisa, elementos essenciais na formação da traquéia. Além disso, não encontramos na literatura nenhum estudo que tenha investigado tais aspectos com a metodologia aqui empregada.

No geral este trabalho mostrou que o uso do corticóide não influenciou as propriedades biomecânicas da traquéia dos animais estudados. A corticoterapia prolongada com metilprednisolona não interferiu nas propriedades biomecânicas de carga no limite de proporcionalidade, carga máxima aplicada, alongamento no limite de proporcionalidade, alongamento máximo, energia absorvida na fase elástica e rigidez das traquéias. Contudo, alguns aspectos merecem ser considerado em relação a tais achados. 
Inicialmente, deve ser enfatizado que neste estudo foram empregados animais adultos que, muito provavelmente, já haviam adquirido uma estabilidade estrutural do tecido traqueal. Caso tivéssemos utilizado animais em crescimento, ou mesmo animais idosos, os resultados poderiam ter sido diferentes. Isso porque ações catabólicas e antiinflamatórias sobre animais em crescimento poderiam levar ao desenvolvimento de tecido fibroso e cartilaginoso mais frágeis no organismo como um todo, e ao nível traqueal em particular. Animais idosos, por sua vez, poderiam igualmente se mostrar mais susceptíveis ao tratamento com metilprednisolona. Essa última afirmação baseia-se no fato de que cães mais idosos apresentam maior conteúdo traqueal de proteinoglicans e menor quantidade de água, tendo maior fragilidade estrutural (HAMAIDE et al. 1998). Além disso, seres humanos idosos são mais susceptíveis a alterações dos tecidos conectivos, como ocorre, por exemplo, em relação à osteoporose.

Dentre os diferentes tecidos que compõem a traquéia, o cartilaginoso é o de maior importância por estar presente em maior número, e por ser diretamente responsável pela resistência da estrutura. A nutrição dos elementos celulares das cartilagens ocorre pelos capilares do conjuntivo envolvente (pericôndrio), já que as cartilagens não são vascularizadas (JUNQUEIRA \& CARNEIRO, 1999). Dessa forma, muito provavelmente, os efeitos catabólicos dos esteróides sobre os anéis cartilaginosos acabam por serem pouco pronunciados se comparados, por exemplo, aos músculos periféricos.

Os estudos anátomo-patológicos realizados, embora avaliados apenas com microscopia óptica comum e de maneira subjetiva pela patologista, não mostraram alterações histopatológicas significantes associadas ao uso da metilprednisolona. Esse fato foi particularmente verdadeiro em relação às estruturas cartilaginosas e musculares, e apontam na mesma direção dos resultados obtidos com os ensaios de tração. Devemos salientar, contudo, que a maioria dos estudos que descreveu alterações celulares pela ação dos esteróides sobre cartilagens articulares for realizadas com microscopia eletrônica. Nossos achados histológicos ainda diferem dos resultados de redução de células epiteliais e atrofia 
muscular lisa descritos por PAVLOVIC et al (1998). Nesse último estudo, porém, o animal utilizado foi o rato e a droga empregada foi a triamcinolona. A natureza diversa da espécie animal e agente químico empregados pode justificar a diferença entre os achados.

A única alteração histológica relacionada ao uso de metilprednisolona foi um pequeno aumento da congestão e do número de capilares ao nível da mucosa traqueal. Esse achado vai ao encontro dos achados previamente descritos por JADCZUK (1998) em porcos com segmentos traqueais reimplantados e tratados com hidrocortisona em doses de $30 \mathrm{mg} / \mathrm{kg} / \mathrm{dia}$.

Em resumo, apesar da administração de $2 \mathrm{mg} / \mathrm{kg} / \mathrm{dia}$ de metil-prednisolona a coelhas adultas ao longo de 21 dias ter cursado com alterações nutricionais significantes, ela não levou a importantes alterações morfológicas traqueais, nem a alterações significantes das suas propriedades biomecânicas avaliadas por ensaio de tração. 


\section{CONCLUSÕES}

O presente estudo permitiu-nos concluir que a administração prolongada de corticosteróides sistêmicos em altas doses:

- leva a redução significante do peso final das coelhas tratadas.

- não cursa com alterações morfológicas ou das propriedades biomecânicas das traquéias desses animais. 


\section{REFERÊNCIAS BIBLIOGRÁFICAS}

ANGELI, A; DÓRIO, A; SARTORI, M.L.; MASERA R.G.; CEOLONI, B.; PROLO, B.; ROCCA, S.; CHIAPPELLI, F. Interactions between glucocorticoids and cytokines in the bone microenvironment. Annals of the New York Academy of Sciences, New York, v.966, p.97-107, 2002.

BEER, H.D.; FASSLER, R.; WERNER, S. Glucocorticoid-regulated gene expression during cutaneous wound repair. Vitamins and Hormones, New York, v.59, p.217239, 2000.

BEHRENS, B. F.; SHEPARD, N.; MITCHELL, N. Alteration of rabbit articular cartilage by intra-articular injections of glucocorticoids. Journal of Bone And Joint Surgery, Boston, v. 57-A, n. 1, p. 70-76, 1975.

BETHLEM, N. Pneumologia. 4.ed. São Paulo: Atheneu, 1996. 957p.

CANALIS, E.; DELANY, A.M. Mechanisms of glucocorticoid action in bone. Annals of the New York Academy of Sciences, New York, v.966, p.73-81, 2002

CARAZZATO, J. G. et al. Estudo experimental das alterações histológicas e biomecânicas induzidas pela infiltração local de corticóide e anestésico. Revista Brasileira de Ortopedia, São Paulo, v.15, n. 2, p. 61-65, 1980.

CHANDLER, G.N.; WRIGHT, V. Deleterious effect of intra-articular hydrocortisone. Lancet, London, v.2, p.661-663, 1958.

CHANDLER, G.N.; WRIGHT, V.; HARTFALL, S.J. Intra-articular therapy in rheumatoid arthritis. Comparison of hydrocortisone tertiary butyl acetate and hydrocortisone acetate. Lancet, London, v.2, p.659-661, 1958.

COBURN, R.F.; PALOMBINI, B. Time dependent pressure-volume relationships of the in vivo canine trachea. Respiration Physiology, Amsterdam, v.16, p.282-289, 1972. 
CRANNEY, A.; WELCH, V.; ADACHI, J. D. HOMIK, J.; SHEA, B.; SUAREZALMAZOR, M. E.; TUGWELL, P.; WELLS, G. Calcitonin for the treatment and prevention of corticosteroid-induced osteoporosis. Cochrane Database System Review, Ottawa, v.2, p.315-345, 2000.

GILMAN, A.; G. As bases farmacológicas da terapêutica. 9 ed. Rio de Janeiro: McGraw-Hill, 1996. 1436p.

GUYTON, A.C. ; HALL, J. E. Tratado de fisiologia da médica. Rio de Janeiro: Guanabara Koogan, 1997. 977p.

HAMAID, A. et al. Effects of age and location on the biomechanical and biochemical properties of canine tracheal ring cartilage in dogs. American Journal of Veterinary Research, Chicago, v.59, n. 1, p.18-22, 1998.

HAMILL, J.; KNUTZEN K. M. Bases biomecânicas do movimento humano. São Paulo: Manole, 1999. 532p.

HANLEY, D. A. et al. Etridronate therapy in the treatment and prevention of osteoporosis. Journal of Clinical Densitometry, Totowa, v. 3, n. 1, p.79-95, 2000.

HUANG, W. H. ; ZHENG. M.H. Steroid hormones and bone. Histology and Histopathology, Murcia, v. 14, p.1257-1268, 1999.

ITANI, T. et al. Quantitative analysis of rough endoplasmic reticulum in chondrocytes of articular and tracheal cartilage of rabbits following the systemic administration of hydrocortisone. Journal Anatomy, London, v. 181, p. 357-363, 1992.

JADCZUK, E. High doses of hydrocortisone improved tracheal autograft revascularization. European Journal of Cardio-thoracic Surgery, Belfast, v. 14, p.615-620, 1998.

JOY, M. S. et al. A multidisciplinary renal clinic for corticosteroid-induced bone disease. Pharmacotherapy, Boston, v. 20, p. 206-216, 2000.

JUNQUEIRA, L. C.; CARNEIRO, J. Histologia básica. 9.ed. Rio de Janeiro: Guanabara Koogan, 1999. 427p.

LIMA, O. et al. Effects of methylprednisolone and azathioprine on bronchial healing following lung autotransplantation. The Journal of Thoracic and Cardiovascular Surgery, St. Louis, v. 82, p. 211-215, 1981. 
MENEZES, D. F. Aplicação do ultra-som terapêutico em lesão muscular experimental aguda. São Carlos, 1997. 40p Dissertação (Mestrado em Bioengenharia) - Escola de Engenharia de São Carlos e Faculdade de Medicina de Ribeirão Preto, Universidade de São Paulo.

MEYERS, A. D. ; BISHOP, H. E. Biomechanical characteristics of the canine trachea. American Journal of Physiology, Bethesda, v. 87, p. 538-543, 1978.

MEYERS, A. D.; BISHOP, H. E.; PETERS, S. Biomechanical characteristics of the human trachea. Otolaryngology Head and Neck Surgery, St. Louis, v. 88, p. 409$411,1980$.

NEGRI, A. L.; PLANTALECH, L. C.; RUSSO PICASSO, M. F.; OTERO, A.; SARLI, M. Osteoporosis postransplante. Medicina, Buenos Aires, v.59, n.6, p.777786, 1999.

PAPACRHISTOU, G.; ANAGNOSTOU, S.; KATSORHIS, T. The effect of intraarticular hydrocortisone injection on the articular cartilage of rabbits. Acta Orthopaedica Scandinavica, Copenhagen,v. 68, p. 132-134, 1997.

PAVLOVIC. D. et al. Effects of corticosteroids on epithelial structure and smooth muscle function of rat trachea. The European Respiratory Journal, Copenhagen, v. 11, p. 575-582, 1998.

PODBIELSKI, A ; RAISS, R. Dose related effects of dexamethasone treatment on the ultrastructure of articular cartilage in rats. Agents and Actions, Basel, v. 17, p.34, 1985.

POWELL, W. Static mechanical properties of the trachea and bronchial tree. Journal of Biomechanics, Elmsford, v.8, p.111-117, 1975.

RAMOS, R. S. Biomecânica: conceito atual. Revista Brasileira de Ortopedia, São Paulo, v.14, p.141-143, 1979.

RANG, H. P.; DALE, M. M.; RITTER, J. M. Farmacologia. 4.ed. Rio de Janeiro: Guanabara Koogan, 2001. 703p.

RANG, H. P.; DALE, M. M.; RITTER, J. M. Pharmacology. 3.ed. New York: Churchill-Livingstone, 1996. 855p.

REID, D. M. et al. Efficacy and safety of daily risedronate in the treatment of corticosteroid-induced osteoporosis in men and wonen: a randomized trial. Journal of Bone and Mineral Research, Cambridge, v. 15, n. 6, p. 1006-1013, 2000. 
ROCHA, M. A. Ensaio mecânico da região epifísio-metafisária: estudo experimental em fêmures de coelhos em crescimento. Ribeirão Preto, 1989. 78p. Tese (Doutorado em Ortopedia e Traumatologia) - Faculdade de Medicina de Ribeirão Preto, Universidade de São Paulo.

ROCKWOOD JÚNIOR, D. et al. Fraturas em adultos. 3.ed. São Paulo: Manole, 1995. 457p.

RUPPEL, C. L. Ventilação. In: SCANLAN, C. L.; WILKINS, R. L.; STOLLER, J. K. (Eds.) Fundamentos da terapia respiratória de Egan. 7.ed. São Paulo: Manole, 2000. p.205-253.

SAMBROOK, P. N. Inhaled corticosteroids, bone density and risk of fracture [comment ]. Lancet, London, v.355, n.9213, p. 1385, 2000.

SANTOS, S. M. Comparação das propriedades mecânicas dos ligamentos coracoacromiais e coracoclaviculares de cadáveres humanos submetidos a ensaios de tração. São Paulo, 1996. 75p. Tese (Doutorado em Ortopedia e Traumatologia) - Escola Paulista de Medicina, Universidade Federal de São Paulo.

SCANLAN, C. L.; WILKINS, R. L.; STOLLER, J.K.(Eds.) Fundamentos da terapia respiratória de Egan. 7. ed. São Paulo: Manole, 2000. 1284p.

SELBY, P. L. et al., Corticosteroids do not alter the threshold for vertebral Fracture. Journal of Bone and Mineral Research, Cambridge, v. 15, n. 5, p. 952-956, 2000.

SHIMANO, A. C.; SHIMANO, M. M. Ensaios tecnológicos de materiais biológicos. In: CONGRESSO BRASILEIRO DE ENGENHARIA BIOMÉDICA, 2000, Florianópolis, 2000. Anais... Florianópolis: CEBEB, 2000. v.1, p.15-21.

SMITH, D.E. et al. Effect of methylprednisolone on angiogenesis in syngeneic rat tracheal gratts. Annals of Thoracic Surgery, Boston, v. 57, p. 652-656, 1994.

SOUZA, S. A. Ensaios mecânicos de materiais metálicos. 5.ed. São Paulo: E. Blucher, 1977. 286p.

SPENCE, A. P. Anatomia humana básica. 2.ed. São Paulo: Manole, 1991. 713p.

STAA, T. P. et al. Use of oral corticosteroids and risk of fractures. Journal of Bone and Mineral Research, Cambridge, v. 15, n. 6, p. 993-1000, 2000.

STEPHENS, N.L.; KRAMER, U. Series elastic component of tracheal smooth muscle. American Journal of Physiology, Baltimore, v.220, p.1890-1895, 1971. 
TARANTINO, A. B. Doenças pulmonares. 4.ed. Rio de Janeiro: Guanabara Koogan, 1997. 709p.

WANG, L. et al. Mechanical properties of the tracheal mucosal membrane in the rabbit. I. Steady-state stiffness as a function of age. Journal of Applied Physiology, Bethesda, v. 88, p. 1014-1021, 2000.

WATERS, R. V. et al. Systemic corticosteroids inhibit bone healing rabbit ulnar osteotomy model. Acta Orthopaedica Scandinavica, Copenhagen v.71, n.3, p. 316$321,2000$.

WEST, J. B. Fisiologia respiratória moderna. 3.ed. São Paulo: Manole, 1990. $188 \mathrm{p}$. 